\title{
The Cleavage Products of Amyloid- $\beta$ Precursor Protein Are Sorted to Distinct Carrier Vesicles That Are Independently Transported within Neurites
}

\author{
Virgil Muresan, ${ }^{1}$ Nicholas H. Varvel, ${ }^{2,3}$ Bruce T. Lamb, ${ }^{2,3}$ and Zoia Muresan ${ }^{1}$ \\ ${ }^{1}$ Department of Pharmacology and Physiology, University of Medicine and Dentistry of New Jersey, New Jersey Medical School, Newark, New Jersey 07103, \\ 2Department of Neurosciences, Lerner Research Institute, The Cleveland Clinic Foundation, Cleveland, Ohio 44195, and ${ }^{3}$ Department of Neurosciences, \\ Case Western Reserve University, Cleveland, Ohio 44106
}

The amyloid- $\beta(\mathrm{A} \beta)$ precursor protein (APP), a transmembrane protein that undergoes proteolytic cleavage into defined fragments, has been implicated in axonal transport. The proposed role of APP as a vesicle receptor for the microtubule motor kinesin-1 has relevance for the pathogenesis of Alzheimer's disease. Nevertheless, this function, which relies on the transport to the cell periphery of full-length APP rather than its cleavage fragments, remains controversial. Other proposed functions of APP, such as regulating transcription, neurogenesis, cell movement, or neurite growth also rely on APP's presence as a full-length protein at the cell surface, implying that APP cleavage occurs after its transport to the cell periphery. To test this hypothesis, we mapped the localization of various APP epitopes in neurons in culture and in the mouse brain. Surprisingly, epitopes from the N-terminal, C-terminal, and central (A $\beta$ ) domains of APP each showed a distinct distribution throughout the cell and rarely colocalized. Within neurites, these epitopes were localized to distinct transport vesicles that associated with different sets of microtubules and, occasionally, actin filaments. C-terminal APP fragments were preferentially transported into neurites as phosphorylated forms, entered the lamellipodium and filopodia of growth cones, and concentrated in regions of growth cone turning and advancement (unlike the $\mathrm{N}$-terminal and $\mathrm{A} \beta$ fragments). We conclude that, under normal conditions, the proteolytic cleavage of APP primarily occurs before its sorting into axonal transport vesicles and the cleaved fragments segregate into separate vesicle populations that reach different destinations, and thus have different functions.

\section{Introduction}

Alzheimer's disease (AD), the prevalent neurodegenerative disorder of old-aged humans, has a complex symptomatology that includes deterioration of cognitive function and progressive memory loss. Although AD has been associated with the presence of neuritic plaques and neurofibrillary tangles in specific brain regions, this symptomatology is likely caused by synaptic dysfunction and neuronal loss (Haass and Selkoe, 2007). What triggers this neuronal pathology is still not known.

An interesting idea is that neuronal degeneration in $\mathrm{AD}$ may be caused by abnormal axonal transport (Kamal et al., 2001; Roy et al., 2005). It was proposed that the transmembrane protein, amyloid- $\beta$ precursor protein (APP), from which the amyloid- $\beta$ peptide $(\mathrm{A} \beta)$ is derived by proteolysis, plays an active role in

\footnotetext{
Received June 9, 2008; revised Jan. 18, 2009; accepted Feb. 12, 2009.

This work was supported by National Institutes of Health Grants GM068596 (V.M.) and AG023012 (B.T.L.) and by the University of Medicine and Dentistry of New Jersey (V.M.,Z.M.). We thank Drs. Dona Chikaraishi and James Wang for providing the CAD cell line, Drs. Samantha Cicero and Karl Herrup for providing the cortical neuron cultures, Drs. Carlos Dotti and Christoph Kaether for providing the APP-YFP CDNA, Drs. Li-Huei Tsai and Ming-Sum Lee for providing the APP-Thr668Glu CDNA, Drs. Brad Hyman and Ayae Kinoshita for providing the C58-GFP CDNA, Dr. Dennis Selkoe for providing the $(9$ anti-APP antibody, and Dr. Karl Herrup for many fruitful discussions and advice.

Correspondence should be addressed to either Zoia Muresan or Virgil Muresan, Department of Pharmacology and Physiology, University of Medicine and Dentistry of New Jersey, New Jersey Medical School, 185 South Orange Avenue, MSB, I-665/I-683, Newark, NJ 07103. E-mail: muresazo@umdnj.edu or muresavi@umdnj.edu.

D01:10.1523/JNEUROSCI.2558-08.2009

Copyright $\odot 2009$ Society for Neuroscience $\quad$ 0270-6474/09/293565-14\$15.00/0
}

transport, by anchoring the plus-end motor kinesin-1 to vesicles that contain APP, the APP processing machinery, and other cargo proteins (Kamal et al., 2000, 2001). In this scenario, a delayed transport may result in premature cleavage of APP into fragments, followed by release of kinesin-1 from the vesicle and early termination of transport. This situation would favor aggregation of $\mathrm{A} \beta$ within the neurites with detrimental consequences on neuronal function and survival (Kamal et al., 2001).

To function as a kinesin- 1 receptor, APP should travel within neurites as an intact protein, capable to anchor the motor to the vesicle. Hence, in normal conditions, a significant fraction of APP should be present within the neuronal processes as full-length protein rather than cleaved polypeptides (see Fig. $1 A$ ). Other proposed functions of APP, such as regulating transcription (Cao and Sudhof, 2001), neurogenesis (Ma et al., 2008), cell movement (Sabo et al., 2001), or neurite growth (Sabo et al., 2003), also rely on APP's presence as full-length protein at the cell surface, implying that APP cleavage occurs after its transport to the cell periphery. This hypothesis was never thoroughly tested for the endogenous APP, with few studies addressing APP transport from the point of view of its proteolytic processing (Buxbaum et al., 1998; Kamal et al., 2001; Lazarov et al., 2002; Goldsbury et al., 2006). This problem can be best explored with immunocytochemistry in neurons expressing normal levels of APP (Muresan and Muresan, 2005b), because exogenous expression of tagged APP (Kaether et al., 2000; Stamer et al., 2002; Goldsbury et al., 
2006) at above-physiological APP levels can perturb its complex metabolism.

To study the potential transport into neurites of APP fragments, as opposed to transport of full-length APP, we mapped the localization of epitopes from different APP regions in neurons in culture and in situ and found that they distribute primarily to nonoverlapping vesicle populations within the neurites. We then showed that phosphorylated C-terminal fragments of APP, but not other APP-derived polypeptides, enter the lamellipodium and filopodia of growth cones (where they codistribute with actin filaments) and become concentrated in regions of growth cone turning and advancement. These results suggest that APP is proteolytically processed before delivery into axons and that the resulting cleavage products are sorted to distinct vesicle populations that are independently transported to different destinations.

\section{Materials and Methods}

Antibodies and mice. The primary antibodies used in this study are as follows: rabbit anti-APP (2452, affinity purified; Cell Signaling Technology) raised against a synthetic peptide corresponding to residues surrounding $\mathrm{Thr}^{668}$ of human APP695; rabbit anti-APP (AB5352, raised to a 9 aa peptide from APP's $C$ terminus; Chemicon); rabbit anti-APP (recognizing residues 676-695 of APP695; C9, affinity purified) (Kimberly et al., 2005); rabbit anti-APP raised against a 22 aa synthetic peptide derived from the $\mathrm{C}$ terminus of APP (CT695, affinity purified; Invitrogen-Zymed); mouse anti-human $A \beta$ (4G8, purified IgG; reacts with an epitope conserved in rodents) and rabbit anti-rodent $\mathrm{A} \beta$ (purified IgG; Signet); rabbit anti- $\beta$-amyloid $1-40$ (AB5074P, affinity purified) and anti- $\beta$-amyloid 1-42 (AB5078P, affinity purified) (Chemicon; these antibodies recognize the free $\mathrm{C}$-terminal end of $\mathrm{A} \beta)$; mouse anti-APP (MAB348, clone 22C11; purified IgG recognizing an $\mathrm{N}$-terminal epitope; amino acids 66-81; Chemicon); rabbit anti-APP, $\mathrm{N}$ terminal (amino acids 46-60; A8967, IgG fraction; Sigma); and mouse anti-Alz 90 (MAB349; purified Ig) raised against a synthetic peptide corresponding to amino acids 511-608 of APP pre-A4 ${ }_{695}$ (Chemicon). A rabbit antibody to phosphorylated APP [pAPP; 44-336Z; raised against a phosphopeptide (containing phospho-threonine) from the region surrounding $\mathrm{Thr}^{668}$ of human APP695; affinity purified and negatively preadsorbed using a corresponding, nonphosphorylated peptide; BioSource International] reacts with phosphorylated, but not nonphosphorylated, forms of APP (Muresan and Muresan, 2005a,b). A mouse antibody to phospho(Thr) mitogen-activated protein kinase/cyclin-dependent kinase substrate (2321) that detects phospho-threonine only when followed by proline was from Cell Signaling Technology. A rabbit antibody to calsyntenin-1 (alcadein- $\alpha$ ) was from Protein Tech Group. Mouse (B-7) and rabbit (M-300) anti-c-Jun $\mathrm{NH}_{2}$-terminal kinase-interacting protein-1 (JIP-1) antibodies were from Santa Cruz Biotechnology. Microtubules were stained with mouse antibodies to $\alpha$-tubulin (B-5-1-1) or to acetylated tubulin (6-11B-1) (Sigma). Actin filaments were stained with a fluorescein-phalloidin conjugate (Invitrogen).

The genomic-based transgenic mouse, R1.40-YAC, containing the human APP (Swedish mutant) gene on a C57BL/6 background, has been described previously (Lamb et al., 1997; Lehman et al., 2003).

Cell culture and transfections. Mouse CNS-derived CAD cells (Qi et al., 1997) were grown in 1:1 F-12/DMEM, containing $8 \%$ fetal bovine serum and penicillin/streptomycin. Differentiation was induced by culturing without serum (Qi et al., 1997). Embryonic day 16.5 mouse cortical neurons were grown in Neurobasal medium with B-27 supplement, L-glutamine, and penicillin/streptomycin for $5 \mathrm{~d}$.

APP-yellow fluorescent protein (YFP) (Kaether et al., 2000), APPThr668Glu (Muresan and Muresan, 2005b), or a green fluorescent protein (GFP)-tagged C-terminal fragment of APP (C58-GFP) (Kinoshita et al., 2002) were transfected into CAD cells using FuGene 6 (Roche Diagnostics).

Preparation of tissue and cell extracts and Western blotting. Brain tissue was collected from male Sprague Dawley rats (killed by asphyxiation with
$\mathrm{CO}_{2}$ ), placed in ice-cold PBS, pH 7.4, and homogenized in HEPESacetate buffer containing 1\% NP-40 (Muresan and Muresan, 2005b). CAD cells were washed with PBS and extracted either in HEPES-acetate buffer containing $2 \%$ Triton X-100 or in Tris- $\mathrm{HCl}$ buffer containing $1 \%$ NP-40 (Muresan and Muresan, 2005b). The extracts were analyzed for the presence of APP by Western blotting (using 10\% SDS-PAGE gels). Antibody incubations were done in the presence or absence of competitor polypeptides at 100:1 molar excess over IgG.

Immunocytochemistry. CAD cells and primary cortical neurons were fixed (20 min in PBS containing 4\% formaldehyde and 4\% sucrose) (Goslin and Banker, 1991), permeabilized (0.3\% Triton X-100, 20 min at $20^{\circ} \mathrm{C}$ ), and processed for single or double antigen labeling as described previously (Muresan and Muresan, 2005b). In some experiments, cells were fixed in $4 \%$ formaldehyde alone (omitting sucrose); in others, fixation ( $4 \%$ formaldehyde) and permeabilization ( $0.1 \%$ Triton X-100) was done simultaneously. Occasionally, cells were fixed and permeabilized for 3-5 min with cold methanol. Secondary antibodies coupled to Alexa dyes (488 and 594) were from Invitrogen. When required, doublelabeling experiments with two primary antibodies raised in rabbit were done by using fluorescently labeled, monovalent Fab fragments of antirabbit IgG (Jackson ImmunoResearch) (Li et al., 2002; Muresan and Muresan, 2005b). Transfected APP-YFP was detected via the YFP fluorescence. For in situ localization of APP, cryosections were cut from fixed (4\% paraformaldehyde, $4^{\circ} \mathrm{C}$, overnight), cryoprotected (30\% sucrose, $4^{\circ} \mathrm{C}$, overnight), and OCT compound-embedded brains from 18month-old R1.40 mice (Yang et al., 2006).

Digital images were obtained with an Olympus IX81 microscope (20, 40 , and $100 \times$ objectives) equipped with Semrock filters and a cooled CCD camera (Hamamatsu Photonics) and collected using Image-Pro Plus software (Media Cybernetics). Images were processed for contrast and brightness with Adobe Photoshop. The distribution of fluorescent particles along neurites was analyzed in thresholded, inverted, grayscale images, using the "plot profile" function of the NIH ImageJ 1.39u software (Muresan and Muresan, 2007).

For colocalization studies of two epitopes viewed in different channels, alignment of the two colors was confirmed through staining of test samples probed with a mouse primary antibody (e.g., anti-JIP-1), followed by a mixture of anti-mouse secondary antibodies tagged with Alexa 488 and Alexa 594. As shown in supplemental Figure $1 U-W$ (available at www.jneurosci.org as supplemental material), there was perfect colocalization of the particle distributions detected in the two channels. The extent of colocalization of epitopes from different APP regions was estimated by quantifying the percentage of coincidence of fluorescent particles between two channels. Briefly, pairs of inverted, grayscale images were thresholded at the mean intensity (determined in Adobe Photoshop CS2), to eliminate most of the diffuse, nonparticulate labeling. The total number of fluorescent particles in each image of the pair and the number of particles common to both images were counted. This procedure provided a better quantitation of particle colocalization than the percentage of pixel overlap between the two channels.

The percentage of distribution of individual APP epitopes among different neuronal compartments (i.e., soma, neurites, and neurite terminals) was determined by quantifying the distribution of fluorescence intensity within each cell using ImageJ software. Surface plot analysis and conversion to mask of fluorescent particle distribution was done using ImageJ software. Statistical analysis was done using a two-sample $t$ test for the two-tailed hypothesis (Zar, 1999). For each experimental condition, data were derived from at least three separate experiments.

Control experiments. Three types of experiments were done to control for nonspecific binding. (1) Nonspecific binding of secondary antibodies was assessed in experiments that omitted the primary antibodies, in which images have been acquired and processed as in the presence of the primary antibodies. (2) The specificity of antibodies for their cognate epitopes was verified in control experiments that used incubation of the specimens in the presence of competing polypeptide used at 100:1 molar excess over IgG (Muresan and Muresan, 2005a,b). We used the following competing polypeptides: $\mathrm{A} \beta 40$ and $\mathrm{A} \beta 42$ peptides, HPLC purity (AnaSpec; peptides were solubilized according to the manufacturer's instructions); a polypeptide that encompassed a 12 aa region centered on 
$\mathrm{Thr}^{668}$ in the APP cytoplasmic domain (termed here "short polypeptide"); and a biotinylated polypeptide encompassing the entire APP cytoplasmic domain (termed here "long polypeptide"). (3) Antibody $22 \mathrm{C} 11$ was preadsorbed on a membrane that contained the APP region of an overloaded transfer of rat brain lyzate (similar to the blot in Fig. 2D) to remove the anti-APP-immunoreactive species from the IgG fraction, or preadsorbed on a membrane that contained transferred BSA. As seen in Figure $2 D$, antibody $22 \mathrm{C} 11$ shows no nonspecific binding even in Western blots that were overloaded with rat brain extract.

The specificity of the anti-pAPP antibody for the phosphorylated, but not nonphosphorylated, APP epitope was verified in Western blots of in vitro phosphorylated versus nonphosphorylated glutathione $S$-transferase (GST) fusions with the APP cytoplasmic domain. In vitro phosphorylation of the fusion proteins was done with bacterially expressed GST-cyclin-dependent kinase 5 (Cdk5) and GST-p25 (an activator of Cdk5) (Iijima et al., 2000). Additional specificity control experiments showing elimination of labeling with the anti-pAPP antibody after incubation with excess, phosphorylated, but not nonphosphorylated, polypeptide corresponding to the APP cytoplasmic domain were described in our previous publications (Muresan and Muresan, 2004, 2005a,b). As specified in the data sheet 013004 for the anti-pAPP antibody (44-336Z), treatment of transfers of CAD cell extracts with $\lambda$-phosphatase completely eliminated antibody binding, showing strict specificity for $\mathrm{pAPP}$.

\section{Results \\ Different APP epitopes show distinct intracellular localization}

Although intensively investigated, transport of APP within neurons is still incompletely understood, especially because of its complex posttranslational modifications, which include phosphorylation and extensive proteolytic processing (Fig. 1A). Although the possibility that a fraction of APP might be transported into neurites as fragments generated by secretase cleavage was occasionally considered (Yamazaki et al., 1995; Buxbaum et al., 1998; Lazarov et al., 2002; Goldsbury et al., 2006), many studies of APP transport in real time used C-terminally tagged APP and assumed that the transport of the tag is representative of that of full-length APP (Kaether et al., 2000; Stamer et al., 2002). However, this approach does not discern between transport of the full-length APP and of the cleaved fragments containing the C-terminal region (CTFs). To begin addressing the transport of endogenous APP in relation to its processing, we used immunocytochemistry to compare the overall patterns of localization of various APP epitopes in neuronal cells (i.e., CAD cells, primary neurons, and neurons in situ), focusing on their general distribution within the cell. We note that immunocytochemistry is the only procedure currently available to investigate localization of endogenous proteins. The antibodies used recognize distinct domains of APP, are well characterized in terms of specificity (Grundke-Iqbal et al., 1989; Weidemann et al., 1989; Hilbich et al., 1993; DeGiorgio et al., 2002; Muresan and Muresan, 2004, 2005a,b) (see also results reported here), and detect both fulllength APP and truncated APP forms containing their cognate site (Fig. 1A; and supplemental Fig. 1T, available at www. jneurosci.org as supplemental material). Importantly, we included in our study antibodies that detect the cleaved C termini of either $\mathrm{A} \beta 40$ or $\mathrm{A} \beta 42$, which selectively bind to these polypeptides. Thus, the combined use of these antibodies should allow determining whether full-length APP or shorter polypeptides derived from APP are being detected.

Immunocytochemistry of cultured CAD cells [a CNS-derived, neuronal cell line (Qi et al., 1997) with relevance to AD (Muresan and Muresan, 2008)] showed that the epitopes corresponding to different domains of APP mostly localize to distinct regions of the cell: the antibodies against the cytoplasmic domain of APP consistently labeled mostly the cell soma, whereas those recognizing epitopes within the $\mathrm{N}$-terminal domain labeled, to a large extent, the neurite terminals (Fig. $1 B, D$,J; and supplemental Fig. $1 A-O$, available at www.jneurosci.org as supplemental material). Antibodies to the $A \beta$ region labeled primarily the neurites (with little or no accumulation at terminals) and the cell bodies (Fig. 1C). A comparable result was obtained with primary cortical neurons (Fig. $1 E-I$ ). Control experiments done (1) in the absence of primary antibodies, (2) in the presence of competing polypeptides, or (3) using negatively preadsorbed antibodies showed that the immunolabeling was specific (Fig. $1 K, L$; and supplemental Fig. 2 , available at www.jneurosci.org as supplemental material). The segregated distribution of APP epitopes was seen under various fixation and permeabilization conditions, including the omission of sucrose from the fixative, simultaneous addition of the detergent and fixative (Fig. 1M-O), or cold methanol fixation (data not shown).

Whereas the pattern of segregation of APP epitopes was similar in most cells, we also noticed subcellular distributions of APP epitopes that differed from those described above (our unpublished results), suggesting that the level of expression and the pattern of processing of APP may occasionally differ among individual cells of similar type (see also Muresan and Muresan, 2006). However, these were exceptions. We also noticed that antibodies recognizing C-terminal epitopes (e.g., C9, AB5352, CT695) occasionally showed accumulations at neurite terminals (supplemental Fig. 1 $P, Q$, available at www.jneurosci.org as supplemental material), a distribution that is typical for the localization of pAPP (Muresan and Muresan, 2005b) (see also supplemental Fig. 7, available at www.jneurosci.org as supplemental material). This terminal localization is likely attributable to the binding of these antibodies to pAPP species, as suggested by double-labeling experiments done with these antibodies and an antibody to pAPP (see below and supplemental Fig. $1 R, S$, available at www.jneurosci.org as supplemental material). Finally, we note that the above-described segregation of epitopes from different regions of APP is typical for differentiated CAD cells and less evident in nondifferentiated cells.

The extensive absence of colocalization of epitopes from different regions of APP indicated that the antibodies primarily detect APP fragments, not full-length APP, suggesting that a significant fraction of intracellular APP is cleaved into fragments. However, these results could also be obtained if, in some parts of the cell, certain epitopes in APP were "masked" by interactions with APP-binding proteins, or otherwise inaccessible to the antibodies. The likelihood of such interactions is increased for the cytoplasmic domain of APP, known to bind proteins that contain phosphotyrosine binding (PTB) domains. To address this concern, we chose for this study antibodies that recognize epitopes in APP outside the region involved in interactions with such proteins (Muresan and Muresan, 2004). As we showed recently, these antibodies can simultaneously detect different APP epitopes on the same vesicle (Muresan and Muresan, 2005b) (see Fig. 7C-E). In addition, Western blots of differentiated CAD cell cultures showed that CAD cells contain significant amounts of APP cleavage products [CTFs and soluble APPs (sAPPs)] (Fig. $2 A, C)$. Also, we have previously shown that CAD cells contain significant amounts of the APP intracellular domain (AICD) (Muresan and Muresan, 2004), as well as A $\beta$ (in monomeric and oligomeric forms) (Muresan and Muresan, 2006), which is consistent with the immunocytochemical observations reported here. However, the fact that the CAD cell cultures maintained in 
A $\digamma^{\text {Signal Peptide }}$

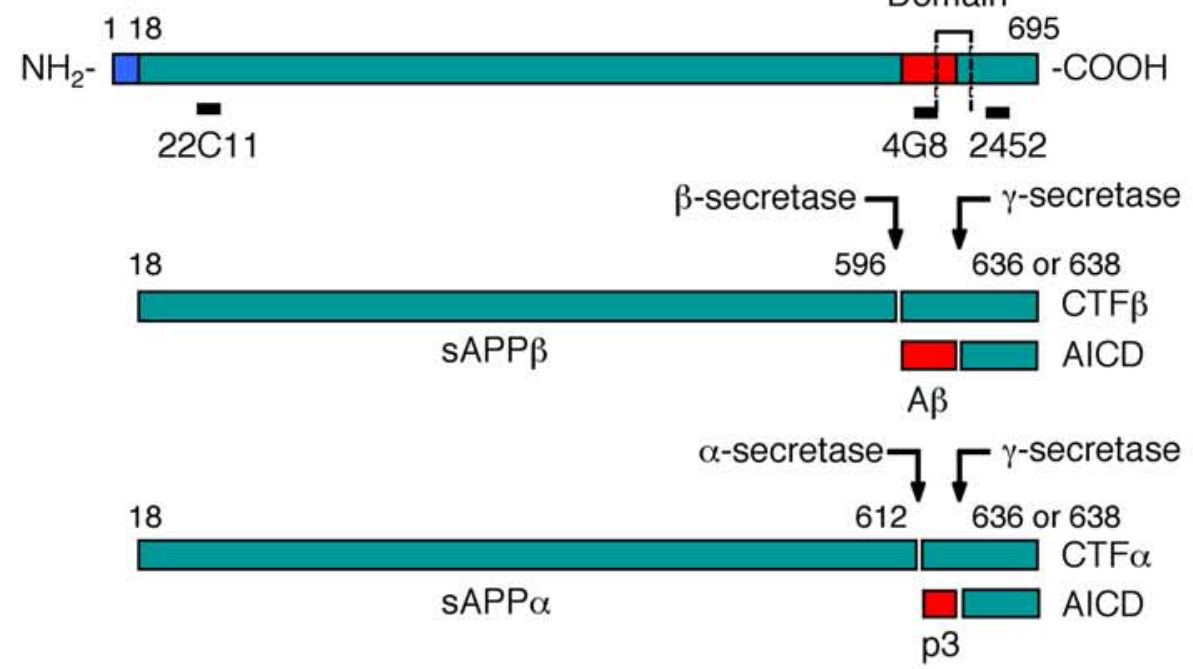

Transmembrane

Domain

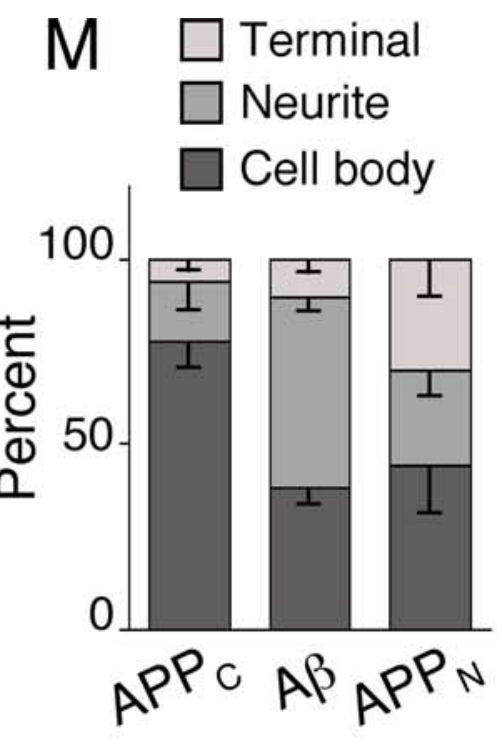

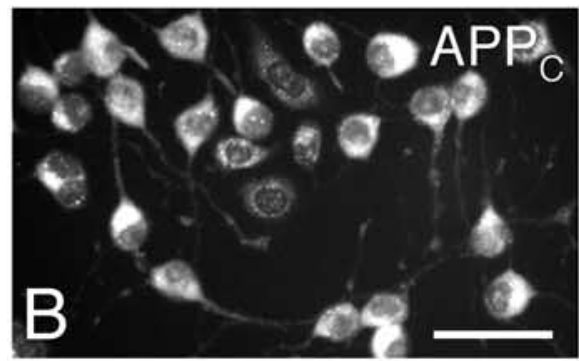
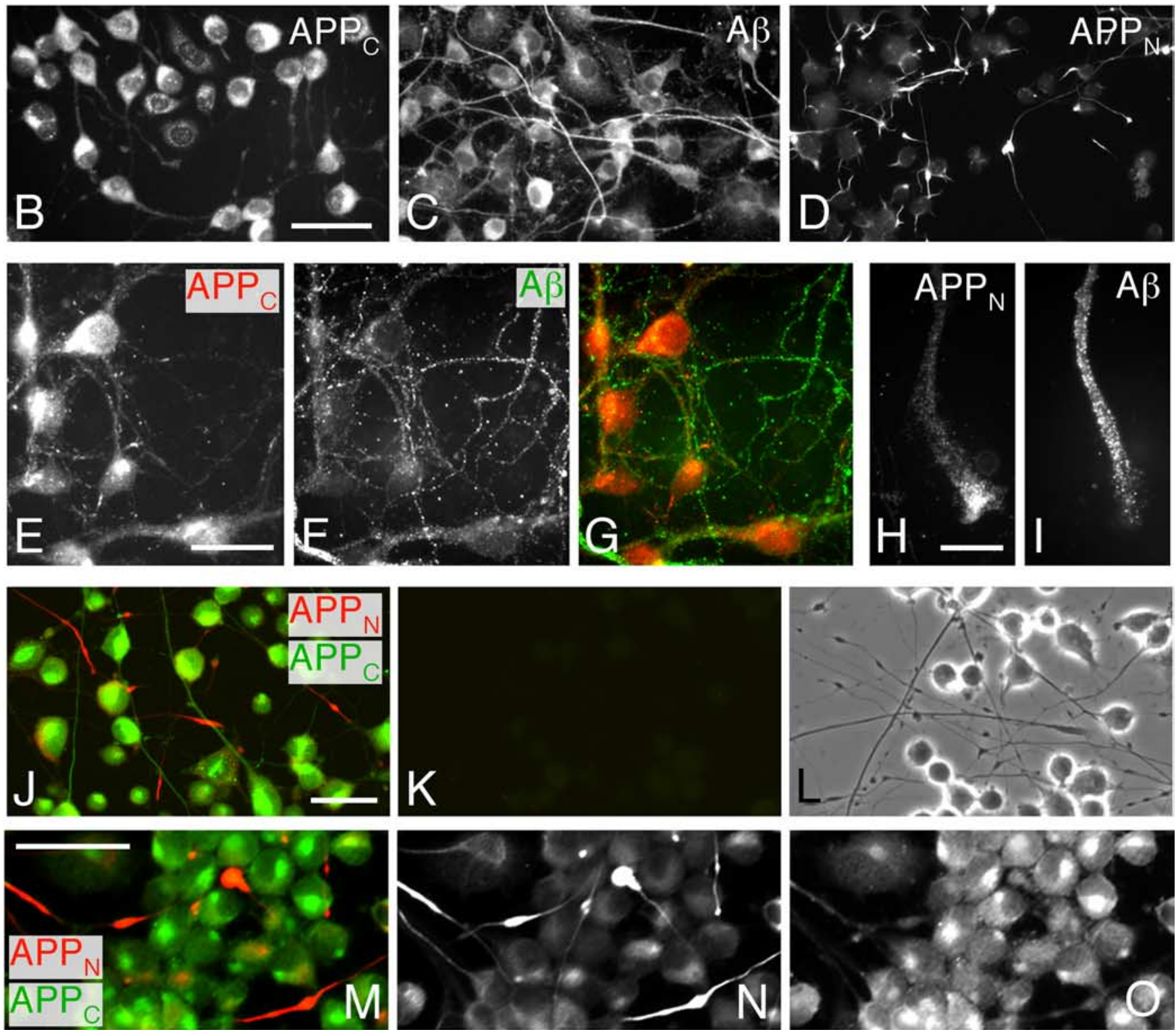

Figure 1. Epitopes from different APP regions do not colocalize. A, Proteolytic processing of APP (modified from Selkoe, 1999). The amyloidogenic (using $\beta$-secretase) and nonamyloidogenic (using $\alpha$-secretase) pathways generate soluble N-terminal domains (sAPPs), a cytoplasmic (-terminal domain (AICD), and middle region polypeptides, A $\beta$ and p3, respectively. The CTFs are intermediary cleavage products. The bars below the top APP diagram show the position of the epitopes recognized by anti-APP antibodies. The anti-pAPP (Figure legend continues.) 
differentiating culturing conditions contain cells that are at various stages during differentiation makes it impossible to directly compare the results of immunocytochemistry with those of Western blots. We conclude that APP fragments are primarily produced intracellularly, not at the cell surface, and are retained within the cell, where they become segregated in different neuronal regions.

\section{Within neurites, epitopes from different APP domains localize to different transport carriers}

The segregation of APP-derived polypeptides could occur by independent transport of the already cleaved polypeptides to the specific intracellular sites. To address whether APP is transported into neurites as full-length protein or as fragments, we studied the relative distribution of epitopes from different APP domains in transport vesicles along the neurites of cultured cells, where individual cargo vesicles can be accurately resolved and analyzed for epitope colocalization. As exemplified in Figure $3 A$, epitopes from the $A \beta$ and $C$-terminal region of APP mostly localize to different transport carriers throughout the processes, indicating that they are transported separately. Control experiments done in the absence of primary antibodies (Fig. 3B) or in the presence of excess polypeptides corresponding to various APP regions (Fig. $3 C, D)$ confirmed the low background labeling and the specificity of binding. Quantification of the vesicle population that contained both APP epitopes indicated that only 21 $\pm 2 \%$ (mean $\pm \mathrm{SD}$ ) of the vesicles that contain APP C-terminal epitopes also contain the $\mathrm{A} \beta$ epitope and thus may carry the full-length APP or the CTFs. Conversely, only $\sim 15 \pm 2 \%$ (mean $\pm \mathrm{SD}$ ) of the vesicles that contain the $\mathrm{A} \beta$ epitope also contain APP C-terminal epitopes, which indicates that many of these vesicles likely contain the $\gamma$-secretase cleavage product (i.e., the AICD). Similarly, vesicles that contain APP N-terminal epitopes were mostly segregated from those containing $\mathrm{C}$-terminal epitopes and the $\mathrm{A} \beta$ peptides, a result that was confirmed with a plethora of antibodies to APP epitopes, including terminal-end-specific anti-A $\beta$ antibodies (supplemental Fig. $3 A-P$, available at www.jneurosci.org as supplemental material). Again, control experiments with excess competitor peptide confirmed specificity of binding (supplemental Fig. 3Q-T, available at www.jneurosci.org as supplemental material). Thus, the transport of APP into neurites occurs, to a large extent, as fragments and not as full-length protein. The processes that determine the

$\longleftarrow$

(Figure legened continued.) antibody detects the phosphorylated version of the epitope recognized by antibody 2452 . The positions of the APP cleavage sites, and of the transmembrane domain, are shown. $\boldsymbol{B}-\mathbf{0}$, Antibodies to $\mathrm{N}$-terminal $\left(\mathrm{APP}_{\mathrm{N}} ; 22 \mathrm{2} 11\right)$ and $\mathrm{C}$-terminal $\left[\mathrm{APP}_{\mathrm{C}} ; 2452\right.$ $(\boldsymbol{B}, \boldsymbol{E}, \boldsymbol{G}), \mathrm{AB} 5352(\boldsymbol{J}, \boldsymbol{M}, \mathbf{O})]$ APP epitopes and to $A \beta(4 G 8)$ show distinct, mostly nonoverlapping labeling patterns in CAD cells $(\boldsymbol{B}-\boldsymbol{D}, \boldsymbol{J}-\boldsymbol{0})$ and cortical neurons $(\boldsymbol{E}-\boldsymbol{I})$. Images in $\boldsymbol{E}-\boldsymbol{G}$ and $\boldsymbol{J}-\boldsymbol{O}$ are from double-labeling experiments. Micrographs in $\boldsymbol{H}$ and $\boldsymbol{I}$ show distal neurites with their terminals. Micrographs in $\boldsymbol{K}$ and $\boldsymbol{L}$ are from a control immunolabeling experiment in which the primary antibodies were omitted. Note that the background labeling attributable to the secondary antibodies is minimal. Micrographs in $\mathbf{M - 0}$ are from an immunolabeling experiment of CAD cells that have been fixed and permeabilized at the same time, using a fixative solution without sucrose. Note that the labeling patterns are similar to those in which cells were permeabilized after fixation $(\boldsymbol{B}-\boldsymbol{J})$. Immunolabeling images with additional anti-APP antibodies, and additional controls, are shown in supplemental Figures 1 and 2 (available at www.jneurosci.org as supplemental material). Scale bars: (in $\boldsymbol{B}, \boldsymbol{J}$, and $\boldsymbol{M}$ ) $\boldsymbol{B}-\boldsymbol{D}, \boldsymbol{J}-\boldsymbol{L}, \boldsymbol{M}-\mathbf{0}, 50 \mu \mathrm{m}$; (in $\boldsymbol{E}$ ) $\boldsymbol{E}-\mathbf{G}, 40$ $\mu \mathrm{m}$; (in $\boldsymbol{H}) \boldsymbol{H}, \boldsymbol{I}, 10 \mu \mathrm{m} . \boldsymbol{M}$, Quantitative measurement of the distribution of APP epitopes within CAD cells. The graph shows, for each of the three epitopes (as detected with the antibodies 22(11, 4G8, and 2452), the percentages that localized to the cell body, neurites (without terminal), and neurite terminals. Error bars indicate -1 SEM.

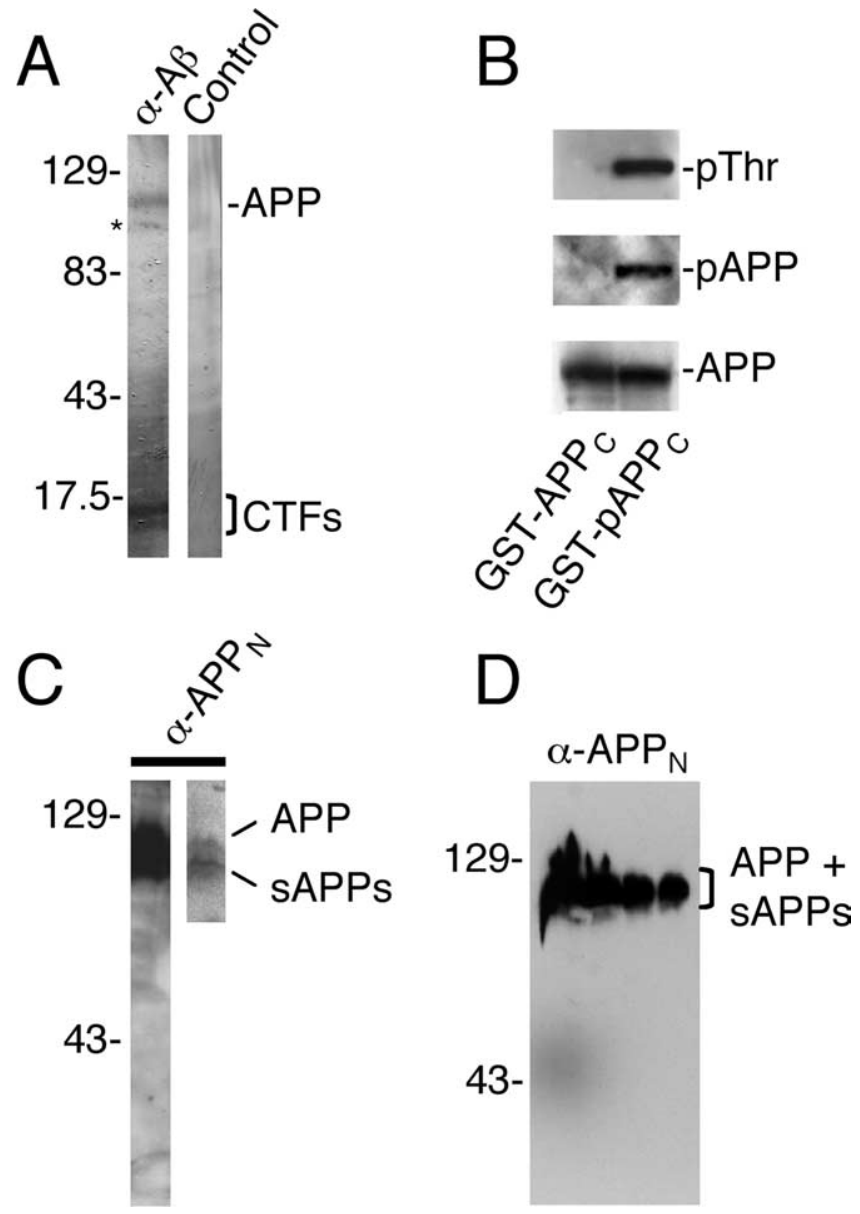

Figure 2. Antibodies used in this study detect full-length APP, cleaved APP fragments, and the phosphorylated, Thr ${ }^{668}$-containing APP epitope. $\boldsymbol{A}, \boldsymbol{C}, \boldsymbol{D}$, Immunoblots of CAD cell $(\boldsymbol{A}, \boldsymbol{C})$ and rat brain $(\boldsymbol{D})$ extracts probed with antibodies to $A \beta(4 \mathrm{G} 8)$ and $A P P N$-terminal epitopes $\left(A_{P P}\right.$; 22(11). $\boldsymbol{A}$, Note that the anti-A $\beta$ antibody detects full-length APP and CTFs and that these protein bands are not detected in the presence of excess, competing $A \beta$ peptide (Control). The asterisk marks a smear on the blot. Although the conditions of this blot are not adequate to detect the small $A \beta$ peptides, we previously showed by Western blotting that $C A D$ cells contain both monomeric and oligomeric forms of $A \beta$ (Muresan and Muresan, 2006). C, The 22C11 antibody stains a broad region corresponding to full-length APP and SAPPs, which are resolved at lower exposure of the blot (right lane). D, No nonspecific binding of antibody $22 \mathrm{C} 11$ in rat brain extract. Lanes contain increasing protein loads, from right to left. Note that even at very high protein loads, the antibody only detects a broad band corresponding to the full-length APP and SAPPs. Molecular weight markers are in kilodaltons. $\boldsymbol{B}$, The anti-pAPP antibody does not recognize the nonphosphorylated APP epitope. Gels were loaded with in vitro phosphorylated (right lanes) and nonphosphorylated (left lanes) GST fusion proteins of the cytoplasmic domain of APP [GST-(p)APP ${ }_{c}$. Antibodies to phosphorylated Thr (pThr) and to pAPP detect the phosphorylated GST-APP fusion protein (GST-PAPP ; right lanes). The antibodies do not detect the nonphosphorylated fusion protein (GST-APP $)$, which was subjected to phosphorylation conditions in the absence of the kinase (left lanes; see Materials and Methods). Both phosphorylated and nonphosphorylated fusion proteins were detected by the antibody to the APP C-terminal domain (AB5352; bottom blots).

relative abundance of the different APP cleavage products within neurites remain to be investigated.

We previously showed that the fraction of APP that is phosphorylated at $\mathrm{Thr}^{668}$ (pAPP) is transported into neurites independently of the nonphosphorylated APP (Muresan and Muresan, 2005b) and that, unlike the more abundant, nonphosphorylated APP, pAPP preferentially accumulates at the neurite terminals. The findings that APP fragments, rather than fulllength APP, are transported along the neurites also raise the possibility that some of the neuritically detected pAPP might repre- 

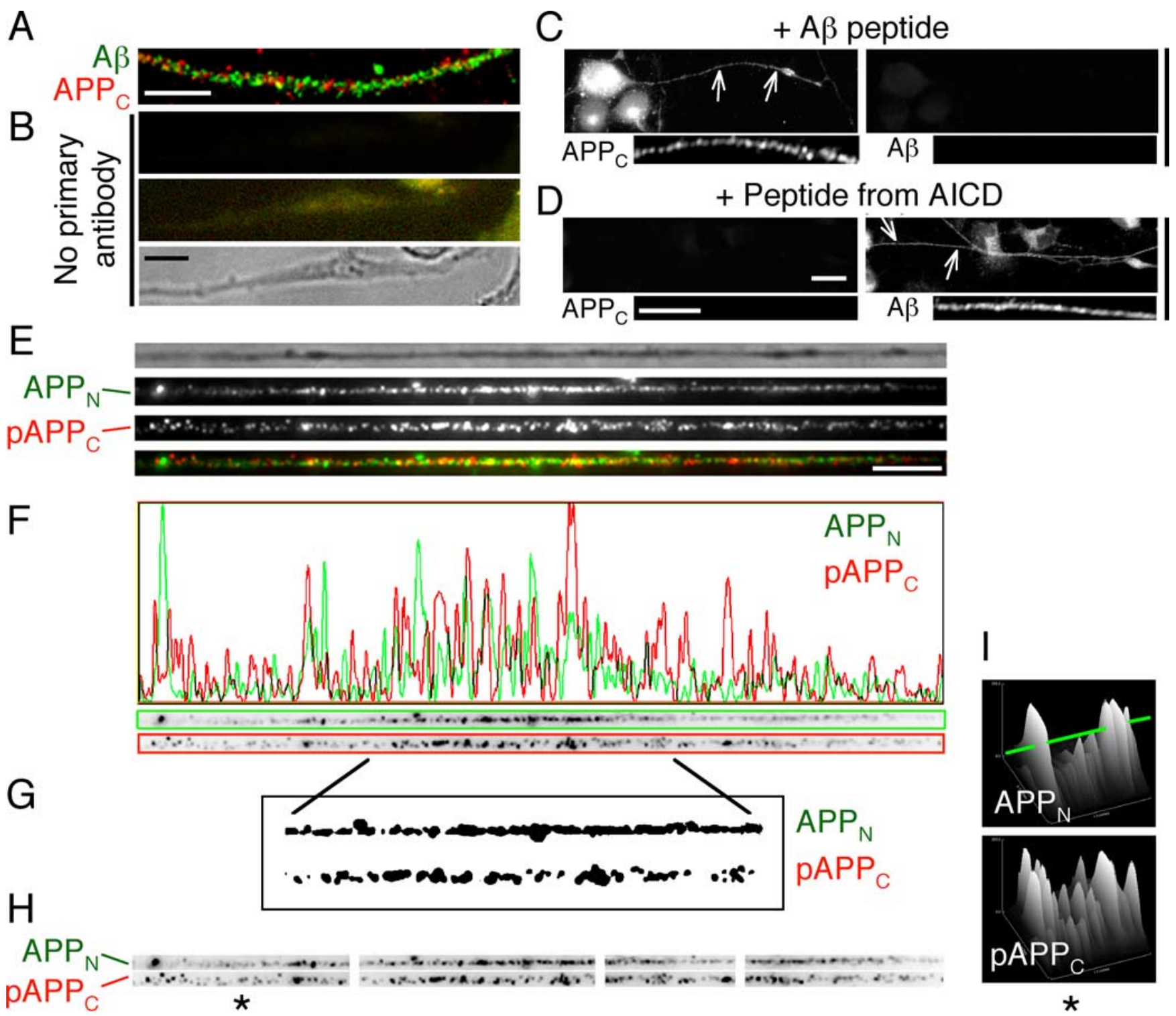

Figure 3. Epitopes from different regions of APP are confined to distinct vesicle populations in CAD cell neurites. $\boldsymbol{A}-\boldsymbol{F}$, Immunolabeling of neurites. The antibodies detect epitopes in the

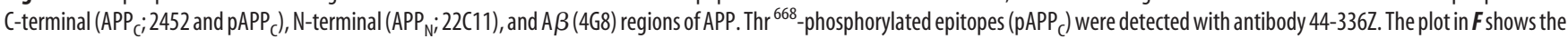
fluorescence distribution of $\mathrm{APP}_{\mathrm{N}}$ and $\mathrm{PAPP}_{\mathrm{C}}$ within the neurite shown in $\boldsymbol{E}$. Inverted, grayscale images (shown below the plot) were used to generate intensity plots that correspond to the distribution of fluorescent particles. Note that there is minimal overlap between the distributions of the peaks in the two channels (compare with Fig. $7 \boldsymbol{F}$ ). The images in $\boldsymbol{B}$ are from a control immunolabeling experiment in which the primary antibodies were omitted. The top image is reproduced at increased contrast in the middle panel. Note that even at extremely enhanced contrast (middle image), the background labeling attributable to the secondary antibodies is low and cannot be confused with the specific, particulate labeling seen with anti-APP antibodies. The bottom image in $\boldsymbol{B}$ and the top image in $\boldsymbol{E}$ are phase-contrast micrographs. $\boldsymbol{C}, \boldsymbol{D}$, Specific detection of $A \beta$ and $A P P_{C}$ by immunocytochemistry. CAD cells were immunolabeled with a mixture of antibodies $4 G 8$ and 2452 in the presence of excess $A \beta$ peptide $(\boldsymbol{C})$ or a polypeptide encompassing the entire APP cytoplasmic domain $(\boldsymbol{D})$. Note that the immunolabeling is abolished only by the corresponding polypeptide. Arrows indicate the neurite segments that are reproduced at higher magnification in the bottom images. Images from the same double-labeling experiment are marked by a side bar. Labeling with the anti-pAPP antibody was prevented by incubation with excess, phosphorylated, but not nonphosphorylated, polypeptide corresponding to the APP cytoplasmic domain (data

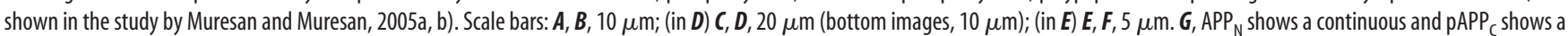
discontinuous distribution along $C A D$ cell neurites. The grayscale images shown in $\boldsymbol{E}$ were converted to masks using ImageJ software. Only the indicated segment of the neurite is shown. Note that $\mathrm{pAPP}_{\mathrm{C}}$ - but not $\mathrm{APP}_{\mathrm{N}}$-containing vesicles appear clustered. $\boldsymbol{H}$, The neurite images shown in $\boldsymbol{E}$ (middle two images) are reproduced as grayscale images that have been inverted and divided into four segments. Each pair of segments has been adjusted for contrast and brightness, to allow clear visualization of the fluorescent particles. Note that $\mathrm{APP}_{\mathrm{N}}$ and $\mathrm{pAPP} \mathrm{C}_{\mathrm{C}}$ are localized to different vesicles along the neurite. $I$, Surface plot analysis of fluorescence distribution of $A_{P P}{ }_{N}$ and PAPP ${ }_{C}$ within the proximal section (marked with *) of the neurite shown in $\boldsymbol{H}$. Note that almost all fluorescent spots corresponding to $\mathrm{APP}_{\mathrm{N}}$ labeling distribute along a single longitudinal line (shown in green), approximately corresponding to the central, longitudinal axis of the neurite. In contrast, $\mathrm{pAPP}_{\mathrm{C}}$ fluorescent particles are broadly distributed through the entire width of the neurite, with large deviations from the central axis. This indicates that the two epitopes have different distribution patterns. The ratio between the length ( $x$-axis) and width ( $y$-axis) of the neurite segment has been altered to allow for better resolution of the bell-shaped, fluorescent particles.

sent phosphorylated CTFs (pCTFs) or phosphorylated AICD (pAICD), not full-length pAPP. We investigated this possibility in very thin processes of CAD cells with antibodies against the ectodomain of APP and with antibodies that specifically recognize the $\mathrm{Thr}^{668}$-phosphorylated forms of APP (Fig. 3E-I). The strict specificity of the anti-pAPP antibody for pAPP species was validated in our previous studies (Muresan and Muresan, 2005a,b) and is reconfirmed here (Fig. 2B). Whereas part of the labeling with the two antibodies was coincident (consistent with the presence of the full-length pAPP), we clearly detected a large 
population of vesicles that stained for the phospho-epitope but not for the N-terminal epitope (Fig. $3 E-H$ ). Quantification of the vesicle population that contained both APP epitopes indicated that only $\sim 19 \pm 4 \%$ (mean $\pm \mathrm{SD}$ ) of the vesicles that contain APP phospho-epitopes also carry N-terminal epitopes (and thus may carry the full-length APP), with the majority likely containing pCTFs and pAICD. Moreover, the distribution pattern of the vesicle populations carrying the two APP epitopes differed significantly, with those containing phospho-epitopes appearing as clusters of vesicles separated by vesicle-free regions (Fig. $3 G$ ).

\section{pAPP polypeptides accumulate at the advancing protrusions of growth cones and may switch from microtubule- to actin- based motility in filopodia}

The segregation of APP N-terminal epitopes from phosphoepitopes was particularly striking at the growth cone, where the latter localized to the peripheral $(\mathrm{P})$ domain and the transition (T) zone, whereas the former localized to the central (C) domain of the growth cone (Fig. 4A-C). Importantly, both epitopes were present in vesicle-like structures that distributed along filamentous tracks, suggesting that these are transport vesicles (supplemental Fig. 4, available at www.jneurosci.org as supplemental material). N-terminal APP epitopes colocalized with the microtubule shaft that entered the growth cone and extended along arc-shaped tracks (likely to be microtubules accompanying F-actin arc structures), which are typical for the T-zone (supplemental Fig. $4 B, D, E$, available at www.jneurosci.org as supplemental material) (Schaefer et al., 2002). APP phospho-epitopes were also present in the $\mathrm{C}$-domain and T-zone, but clearly on different tracks than the APP N-terminal epitopes (supplemental Fig. $4 A, F-H$, available at www.jneurosci.org as supplemental material). In addition, the phospho-epitopes were detected throughout the P-domain of the growth cone, where they aligned along filamentous tracks that extended into filopodia (supplemental Fig. $4 C$, available at www.jneurosci.org as supplemental material).

The above-described distribution of APP phospho-epitopes was typical for growth cones with wide, flattened lamellae, not yet committed to turning the direction of advancement (we call these growth cones "exploratory" growth cones). In contrast, in turning growth cones, committed to a new direction of extension, the APP phospho-epitopes showed a polarized distribution, with high concentration within the advancing protrusions (Fig. $4 D-G$; and supplemental Fig. 5A-D, available at www. jneurosci.org as supplemental material). In such protrusions, the APP phospho-epitopes codistributed with microtubules (Fig. $4 H, I$; and supplemental Fig. 5A-D, available at www. jneurosci.org as supplemental material). A different situation was found in filopodia that surrounded the growth cone, where APP phospho-epitopes extended to the tip of the filopodia, beyond the stable microtubules (Fig. $4 \mathrm{~J}-\mathrm{O}$ ). A similar distribution was seen in the thin, filopodia-like processes emanating laterally from the main neuronal process (Fig. $4 P-R$; and supplemental Fig. $5 E, F$, available at www.jneurosci.org as supplemental material), which are typical for CAD cells (Li et al., 2005; Muresan and Muresan, 2006). Filamentous actin, detected with phalloidin, was found throughout the filopodia and filopodia-like lateral processes (Fig. $5 A-G)$, suggesting that APP phospho-epitopes may penetrate into filopodia by moving on actin filaments rather than microtubules, a hypothesis that will be tested in future studies. Interestingly, APP N-terminal and, to some extent, $A \beta$ epitopes were less abundant in filopodia or filopodia-like processes (Fig. $5 H-R$ ), in line with our hypothesis that APP-derived polypeptides are independently transported to different destinations.

The results described above indicate that pAPP C-terminal fragments, including the pAICD, are being transported into neurites, clearly in association with vesicle-like particles. Moreover, we found that an exogenously expressed, GFP-tagged AICD becomes phosphorylated and some of the pAICD-GFP is transported to the neurite terminals in vesicle-like structures (supplemental Fig. 6, available at www.jneurosci.org as supplemental material). How the pAICD, which is presumably soluble and localizes in part to the nucleus (Muresan and Muresan, 2004), could become associated with transport vesicles remains to be established in future studies.

\section{Different APP epitopes are transported along different microtubule tracks, for which they select early during the secretory pathway}

A close examination of the distributions of the different APP epitopes showed that these are likely transported along different microtubule tracks within neurites. For example, whereas $\mathrm{N}$-terminal APP fragments are transported along a limited set of tracks in the central portion of the neurites, fragments containing $\mathrm{C}$-terminal and $\mathrm{A} \beta$ epitopes are distributed throughout the entire width of the process, apparently being transported along a larger set of microtubule tracks (Fig. 3I; and supplemental Fig. $3 E-P$, available at www.jneurosci.org as supplemental material). In vivo, microtubules are subjected to posttranslational modification in several ways, including acetylation and detyrosination of $\alpha$-tubulin (Luduena et al., 1992). Because the motility properties of kinesin-1 along microtubules with different posttranslational modifications differ (Reed et al., 2006; Dunn et al., 2008), it was possible that transport of the different APP fragments occurs along sets of microtubules that are differentially altered by such modifications. In support of this hypothesis, we found that APP $\mathrm{N}$-terminal fragments, but not CTFs and $\mathrm{A} \beta$ peptides, colocalized strictly with acetylated microtubules (supplemental Fig. 7A-T, available at www.jneurosci.org as supplemental material). pAPP species and JIP-1, a protein that is cotransported with pAPP (Muresan and Muresan, 2005b), showed a distribution pattern distinct from that of acetylated microtubules (supplemental Figs. $7 G-R, 8 E-H$, available at www. jneurosci.org as supplemental material). In contrast, calsyntenin-1, a protein reported to localize to the central region of growth cones (Konecna et al., 2006), showed a distribution typical for the acetylated microtubules and localized to regions that also contained N-terminal APP epitopes (supplemental Fig. $8 A-D$, available at www.jneurosci.org as supplemental material), suggesting that calsyntenin-1 and APP $\mathrm{N}$-terminal fragments use similar transport pathways. Importantly, we found that the segregation of APP N- from C-terminal epitopes, with the confinement of the former to distinct filamentous tracks, occurs already in the cell body, before entrance into neurites. This was particularly evident in cells with flattened neurites, such as the one depicted in supplemental Figure 7, $U$ and $V$ (available at www.jneurosci.org as supplemental material).

Together, these results indicate that, in cultured neurons, APP is proteolytically processed before sorting into transport vesicles and the polypeptides derived from it are transported within neurites independently, packaged in separate transport vesicles. 

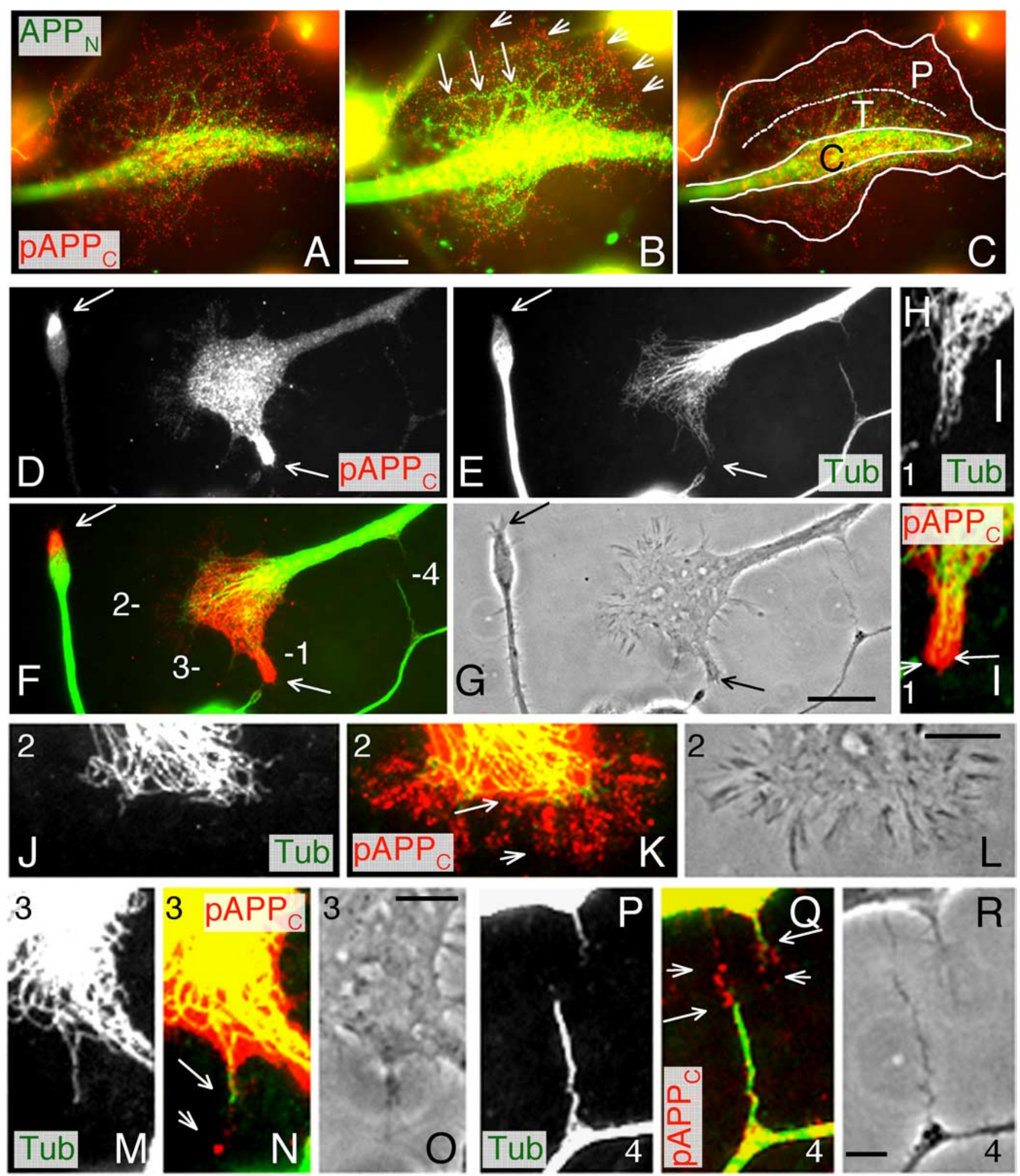

Figure 4. APP (-terminal, phospho-epitopes $\left(\mathrm{AAPP}_{\mathrm{C}}\right)$, but not N-terminal epitopes $\left(\mathrm{APP}_{\mathrm{N}}\right)$, localize to peripheral regions of lamellipodia, and to filopodia, and accumulate in advancing protrusions of growth cones. $\boldsymbol{A}-\boldsymbol{C}$, Immunolabeling of an exploratory growth cone. $\boldsymbol{A}$ is shown at enhanced contrast in $\boldsymbol{B}$. Note that the labeling of both $\mathrm{APP}_{\mathrm{N}}$ (arrows) and pAPP ${ }_{C}$ (arrowheads) is particulate. $\mathrm{APP}_{\mathrm{N}}$ epitopes clearly align along filamentous tracks, which extend from the central domain (C) into the transition zone (T), but not into the peripheral domain (P) of the lamellipodium. C, The periphery and the three characteristic regions (C, T, P) of the lamellipodium. Note that only pAPP ${ }_{C}$ localizes to filopodia, at the periphery of the lamellipodium (see also supplemental Fig. 4 , available at www.jneurosci.org as supplemental material). Scale bar, $10 \mu \mathrm{m} . \mathbf{D}-\mathbf{G}, \mathrm{pAPP}$ accumulates within advancing protrusions (arrows) and mark the direction of turning and advancement of "committed" growth cones. The distribution of microtubules (Tub; anti-tubulin staining) is also shown. $\boldsymbol{F}$, Micrograph regions, shown at higher magnification and increased contrast in $\boldsymbol{H}-\boldsymbol{R}$, are indicated by numbers. $G$, A phase-contrast micrograph. Scale bar, $20 \mu \mathrm{m}$. $\boldsymbol{H}, \mathbf{I}$, Microtubules (Tub) and pAPP $\mathrm{C}_{\mathrm{C}}$ extend up to the tip of an advancing protrusion (marked by arrow and arrowhead) in the turning growth cone shown in $\boldsymbol{D}-\mathbf{G}$. Scale bar, $5 \mu \mathrm{m}$. $\boldsymbol{J}-\boldsymbol{R}, \mathrm{pAPP}$ e extends beyond the microtubule tips (marked by arrows) in growth cone filopodia $(\boldsymbol{J}-\mathbf{0})$ and thin, lateral, filopodia-like processes extending from the main process $(\boldsymbol{P}-\boldsymbol{R})$. Note that pAPP ${ }_{\mathrm{C}}$ vesicles enter filopodia up to their tips (arrowheads). Examples are from the growth cone shown in $\mathbf{D}-\mathbf{G}$. $\mathbf{L}, \mathbf{O}, \boldsymbol{R}$, Phase-contrast micrographs. Scale bars: (in $\mathbf{O}$ and $\boldsymbol{R}) \boldsymbol{M}-\boldsymbol{R}, 5 \mu \mathrm{m}$; (in $\boldsymbol{L}) \boldsymbol{J}-\boldsymbol{L}, 10 \mu \mathrm{m}$. 

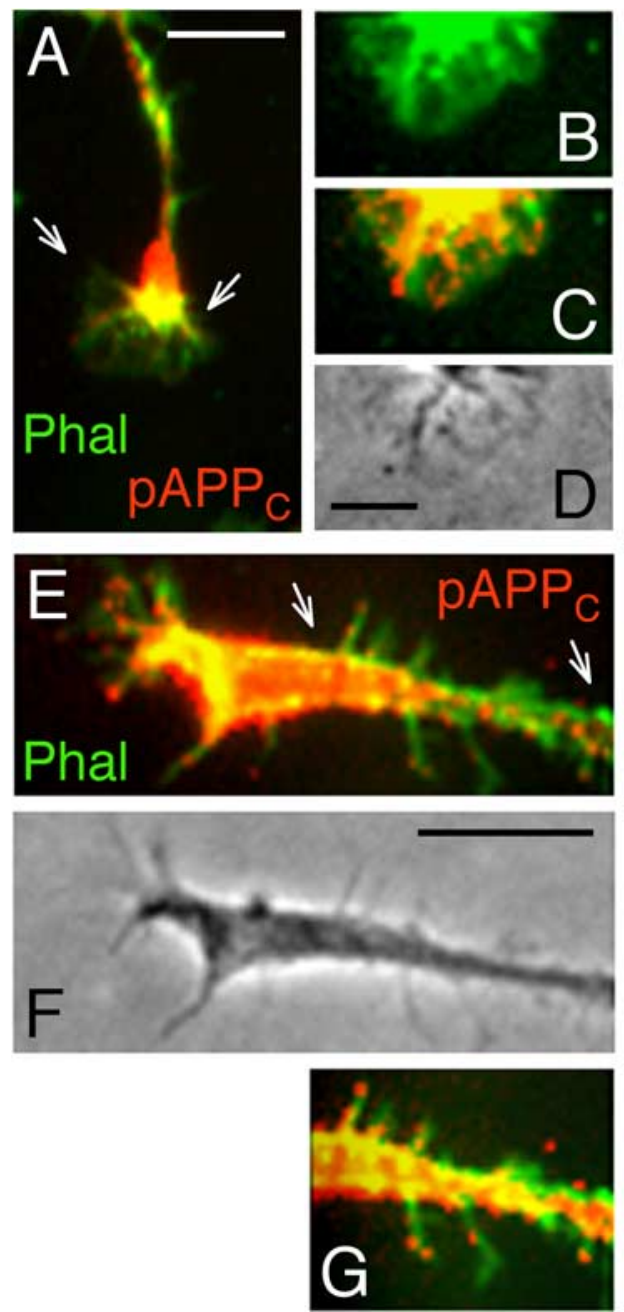
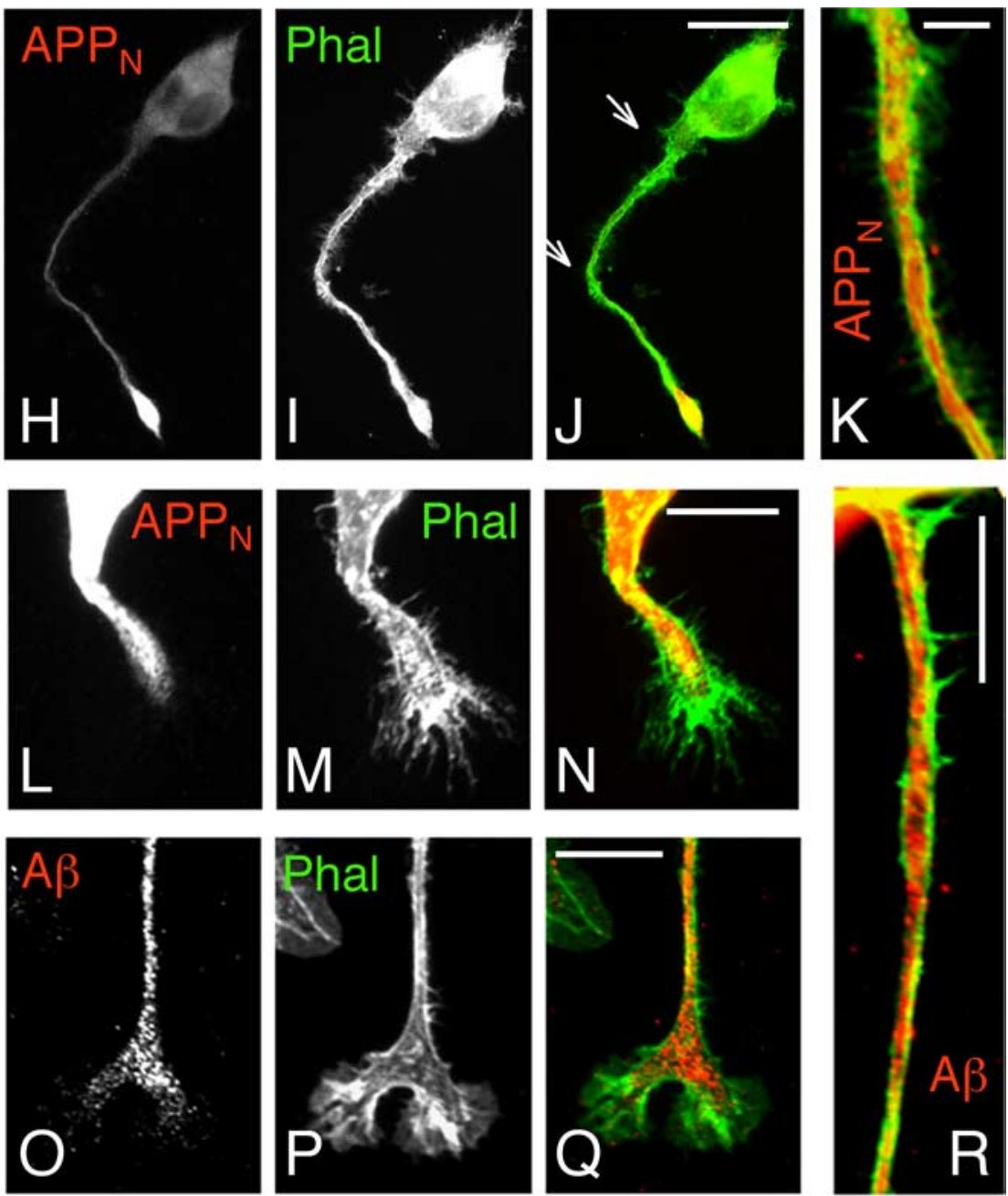

Figure 5. APP (-terminal, phospho-epitopes $\left(\mathrm{pAPP}_{\mathrm{C}}\right)$, but not N-terminal epitopes ( $\mathrm{pAPP}_{\mathrm{N}}$ ), localize to actin-rich regions of the lamellipodium, filopodia, and filopodia-like lateral processes

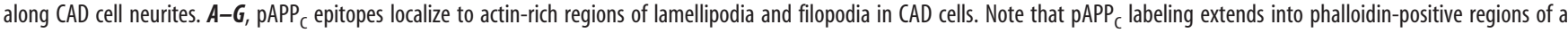
lamellipodium $(\boldsymbol{A}-\boldsymbol{D})$ and filopodia $(\boldsymbol{E}, \boldsymbol{F})$ of advancing growth cones and of lateral filopodia-like structures extending from the main process $(\boldsymbol{E}-\boldsymbol{G})$. The regions between the two arrows in $\boldsymbol{A}$ and $\boldsymbol{E}$ are reproduced at higher contrast in $\boldsymbol{B}, \boldsymbol{C}$, and $\mathbf{G}$, to allow for better detection of pAPP ${ }_{C}$ within filopodia. Note that, unlike microtubules (see Fig. $4 H_{\text {, }} ;$; and supplemental Fig. 5 , available at www.jneurosci.org as supplemental material), actin filaments extend to the tip of filopodia, in regions that also contain pAPP. $\boldsymbol{D}, \boldsymbol{F}$, Phase-contrast micrographs. Scale bars: (in $\boldsymbol{A}$ and $\boldsymbol{F}) \boldsymbol{A}, \boldsymbol{E}$ - $\boldsymbol{G}, 10$ $\mu \mathrm{m}$; (in $\boldsymbol{D}) \boldsymbol{B}-\boldsymbol{D}, 5 \mu \mathrm{m}$. $\boldsymbol{H}-\boldsymbol{N}$, Distribution of $\mathrm{APP}_{\mathrm{N}}$ epitopes, detected with antibody $22 \mathrm{C} 11$. Note that $\mathrm{APP}_{\mathrm{N}}$ epitopes do not penetrate into actin-rich regions of lamellipodia and filopodia ( $\boldsymbol{K}-\boldsymbol{N}$ ). The region between the two arrows in $\boldsymbol{J}$ is reproduced in $\boldsymbol{K}$. $\mathbf{O}-\boldsymbol{R}$, Distribution of $A \beta$ epitopes, detected with antibody $4 G 8$. Note that $A \beta$ epitopes occasionally penetrate into the lamellipodium $(\mathbf{O}-\mathbf{Q})$ and the filopodia-like extensions along neurites $(\boldsymbol{R})$. Images in $\boldsymbol{K}-\boldsymbol{R}$ are shown at high contrast. Scale bars: (in $\boldsymbol{J}) \boldsymbol{H}-\boldsymbol{J}, 40 \mu \mathrm{m} ; \boldsymbol{K}, 10 \mu \mathrm{m}$; (in $\boldsymbol{N}, \mathbf{Q}$, and $\boldsymbol{R}) \boldsymbol{L}-\boldsymbol{R}, 20 \mu \mathrm{m}$. Phal, Phalloidin-positive regions.

\section{Different APP epitopes are segregated in the brain}

We asked whether the segregation of APP epitopes found in CAD cells and primary neurons in culture also occurs in brain neurons, in situ. To answer this question, we used the transgenic mouse R1.40-YAC that expresses an AD-specific mutant of the human APP at low levels (twofold to threefold higher than endogenous APP levels) (Lamb et al., 1997; Lehman et al., 2003). We focused on the Purkinje cells in the cerebellum, which are ideally laid out in the tissue to allow concomitant examination of APP distribution in the cell body and throughout the processes. As shown in Figure 6, the antibodies to C- and N-terminal epitopes of APP labeled the cell bodies and the distal dendritic segments of Purkinje cells, respectively. An antibody to $A \beta$ labeled the cell bodies and proximal dendritic arborizations, but not the distal processes. These labeling patterns reiterate the segregated distribution of these APP epitopes detected in cultured neurons and support the notion that APP polypeptides are transported independently to different intraneuronal destinations.
Unlike endogenous APP epitopes, different epitopes of overexpressed APP do colocalize

The segregation of epitopes from different regions of APP seen in nontransfected cells was less evident in neurons that overexpressed APP. Indeed, unless cells expressed low levels of exogenous APP (Fig. $7 G-K$ ), the epitopes from different regions of overexpressed APP colocalized throughout the neurites and at their terminals (Fig. 7A-F). A typical example pertinent to the detection of APP phospho-epitopes is shown in Figure 7C-F, where CAD cells expressing the phospho-mimetic APP mutant APP-Thr668Glu were stained with antibodies to $A \beta$ and to the C-terminal phospho-epitope. Quantification of the vesicle population that contained both APP epitopes indicated that $\sim 93 \pm$ $13 \%$ (mean $\pm \mathrm{SD}$ ) of the vesicles that contain APP phosphoepitopes may carry the full-length APP, a result that is in sharp contrast to the results obtained for endogenous APP epitopes (Figs. 1, 3; and supplemental Figs. 1, 3, available at www. jneurosci.org as supplemental material). We conclude that pro- 
cessing and transport of APP into neurites is mostly dependent on the level of expression of APP.

\section{Discussion}

APP-derived polypeptides are sorted into separate vesicle populations that reach different intracellular

\section{destinations}

In this study, we have addressed the transport of endogenous APP in relation to its proteolytic processing. To our surprise, we found that APP is transported into neurites as already cleaved polypeptides rather than full-length protein (Fig. 8). Within neurites, these APP cleavage products are detected within distinct transport carriers that associate with different sets of microtubules; some of the APP fragments occasionally codistribute with actin filaments, not microtubules. These results indicate that the proteolytic cleavage of APP primarily occurs before its final sorting into cargo vesicles and that the cleaved fragments segregate into separate vesicle populations that reach different destinations within the cell soma, neurites, and their growth cones. We then showed that phosphorylated C-terminal fragments of APP (including the pAICD), but not other APP-derived polypeptides, enter the lamellipodium and filopodia of growth cones and become concentrated in regions of growth cone turning and advancement. Finally, we showed that these fragments might switch from a microtubule-based transport powered by kinesin-1 (operating within the neurite) to actin-based motility (operating in filopodia). Overall, our results overturn the long-held view according to which transport of APP within neurites occurs, under normal conditions, mostly as full-length protein.

The findings that much of the intracel-

lular APP is present as cleaved fragments and that the cleaved fragments are transported into neurites and accumulate at the terminals should not be unexpected. Indeed, Buxbaum et al. (1998) found a surprisingly high content of CTFs at presynaptic terminals of entorhinal neurons; Amaratunga and Fine (1995) found that APP is transported along the axons of retinal ganglion cells as proteolytically processed protein; and Lee et al. (2003) reported the presence of significant amounts of phosphorylated CTFs in mouse brain neurons. Most importantly, Sambamurti et al. (1992) presented evidence ( $>16$ years ago) that in PC12 cells APP is cleaved intracellularly in the trans-Golgi network (TGN) or a post-Golgi compartment and that the generated sAPP is then transported in vesicles and exocytosed. Our results are fully consistent with all these previous reports.

More recent data showed that in the mouse brain, the levels of sAPP significantly exceed those of full-length APP (Bai et al., 2007). This situation is also confirmed by results of immunoprecipitation experiments done to identify APP-interacting proteins in vivo, which showed that antibodies to the extracellular $(\mathrm{N}$ -
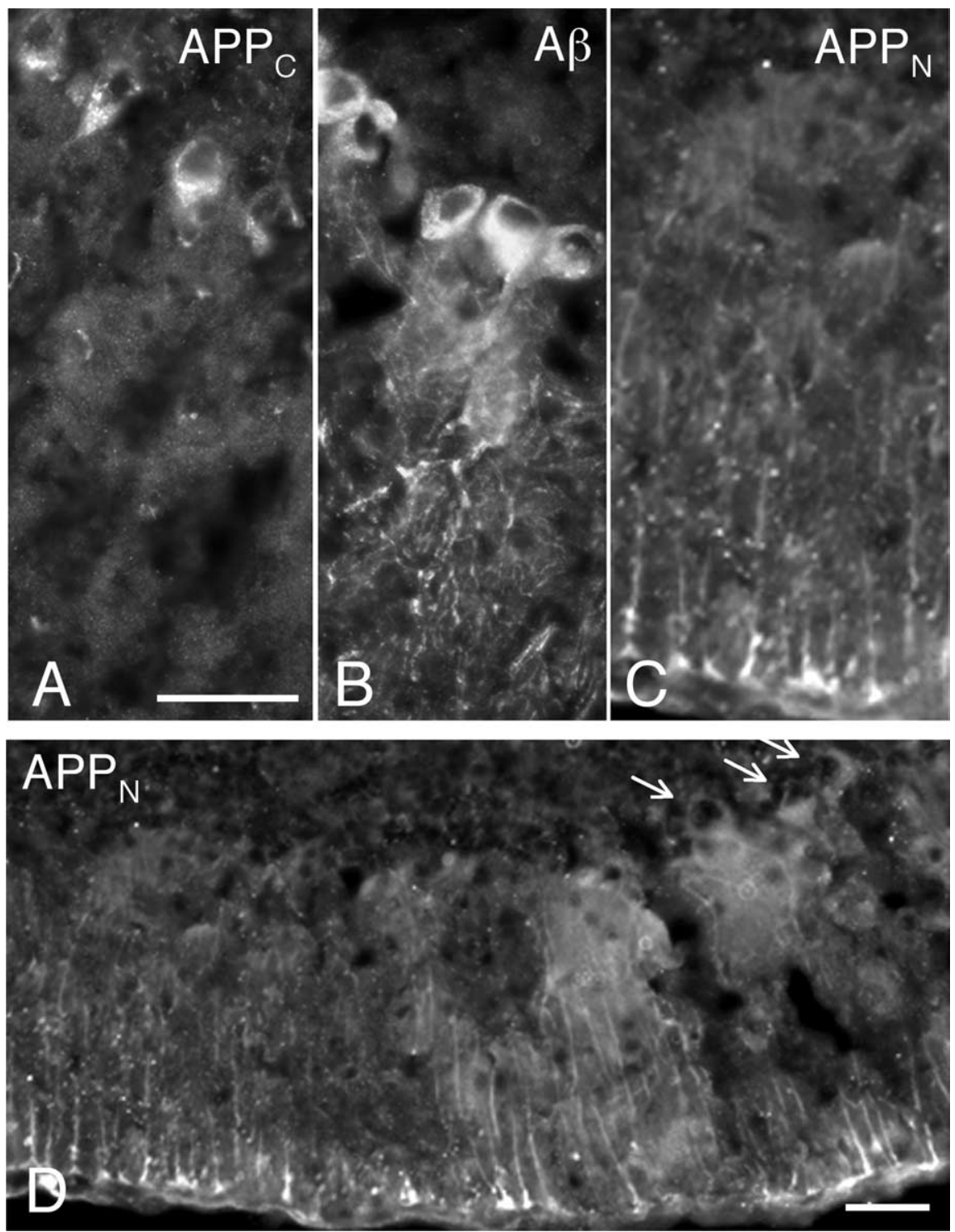

Figure 6. Detection of APP in cryosections from R1.40 mouse brain. $A-C$, Antibodies to $($-terminal $(A P P)$ and $N$-terminal $\left(A P P_{N}\right)$ APP epitopes and to $A \beta$ show distinct labeling patterns in Purkinje cells of the cerebellum. $D$, Low-magnification image of the region that includes the area shown in $\boldsymbol{C}$. Arrows point to cell bodies. Scale bars: (in $\boldsymbol{A}$ and $\boldsymbol{D}$ ), $40 \mu \mathrm{m}$.

terminal) and intracellular (C-terminal) domains of APP coprecipitated distinct, mostly nonoverlapping sets of proteins (Bai et al., 2007). Such a result can only be explained if the intracellular and extracellular APP epitopes are part of distinct polypeptides, which supports the conclusion that a significant fraction of APP is present as cleaved fragments, rather than full-length protein, in the mouse brain, in vivo.

APP processing by the secretase pathways is temporally and spatially regulated (De Strooper and Annaert, 2000), and the precise identification of the intracellular sites where the APP processing events occur is difficult. One reason for this situation is that localization studies of the components of $\alpha-, \beta$-, or $\gamma$-secretase do not provide information on their activation status. The $\gamma$-secretase complex, although probably inactive, assembles in the endoplasmic reticulum (ER) (Annaert et al., 1999; Kim et al., 2007), whereas BACE ( $\beta$-secretase) is detected in the TGN and endosomes (Walter et al., 2001; He et al., 2007). Moreover, activation of $\gamma$-secretase requires proteolytic cleavage of the presenilins themselves (Capell et al., 1998). APP cleavage may thus 

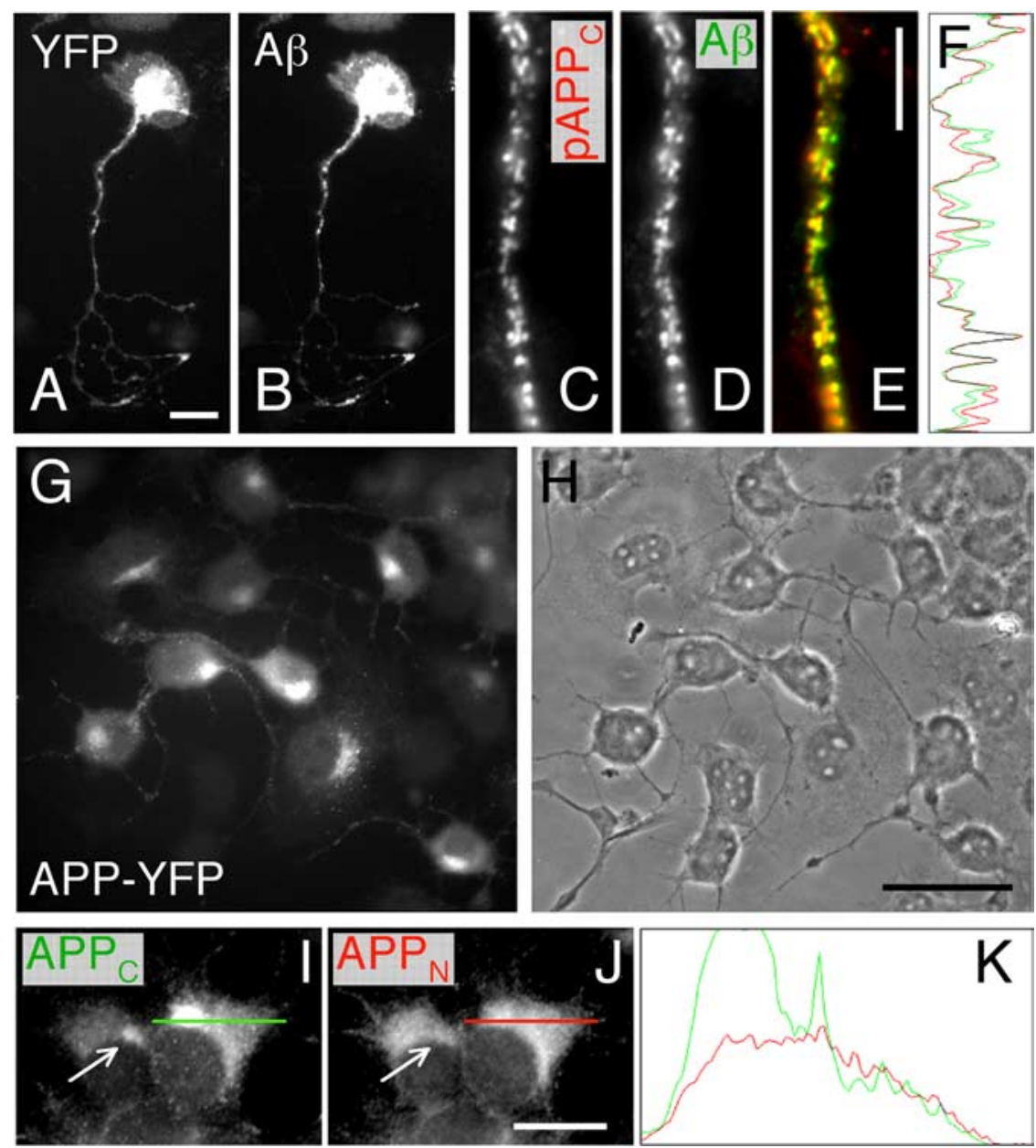

Figure 7. Localization of APP epitopes at high and low APP expression levels. $A, B$, Epitopes from different regions of APP do colocalize in CAD cells expressing APP at high levels. Images show a CAD cell transfected with C-terminally tagged APP-YFP. The C terminus was detected via the YFP tag; $A \beta$ was detected with antibody 4G8. Scale bar (in $A$ ), $25 \mu \mathrm{m}$. C $-\boldsymbol{E}$, Antibodies to pAPP and $A \beta$ label the same vesicle population in CAD cells transfected with the phospho-mimetic APP mutant APP-Thr668Glu, where the constitutively phosphorylated APP is expressed at high level. Scale bar (in $E$ ), $5 \mu \mathrm{m}$. $\boldsymbol{F}$, Intensity plots corresponding to the distribution of $\mathrm{pAPP}_{\mathrm{C}}$ and $A \beta(C, D)$. Note that there is extensive overlap between the distributions of the peaks in the two plots (compare with Fig. 3F). $\boldsymbol{G}, \boldsymbol{H}$, CAD cells expressing low levels of APP-YFP. The APP ( terminus (visualized via the YFP tag) is detected primarily in the cell soma, similar to the endogenous situation (compare with Fig. $1 B$ and supplemental Fig. $1 A-I$, available at www.jneurosci.org as supplemental material). $\boldsymbol{H}$, Phase-contrast micrograph. Scale bar (in $\boldsymbol{H}$ ), $40 \mu \mathrm{m}$. $\boldsymbol{I}, \boldsymbol{J}$, , CAD cells expressing low levels of exogenous APP. The APP ( terminus ( $\left.A P P{ }_{C}\right)$, but not the $N$ terminus $\left(A P_{N}\right)$, is concentrated in the Golgi region. The arrow points to a similar accumulation of $A P P_{C}\left(\right.$ but not $\left.A P P_{N}\right)$ in an adjacent cell. Fluorescence intensity plots along the lines are shown in $\boldsymbol{K}$. Scale bar (in $\boldsymbol{J}$ ), $20 \mu \mathrm{m} . \boldsymbol{K}$, Intensity plots corresponding to the distribution of $\mathrm{APP}_{\mathrm{C}}$ and $\mathrm{APP}_{\mathrm{N}}$ along the colored lines shown in / and J. Note that the two APP epitopes show different distributions within the cell soma.
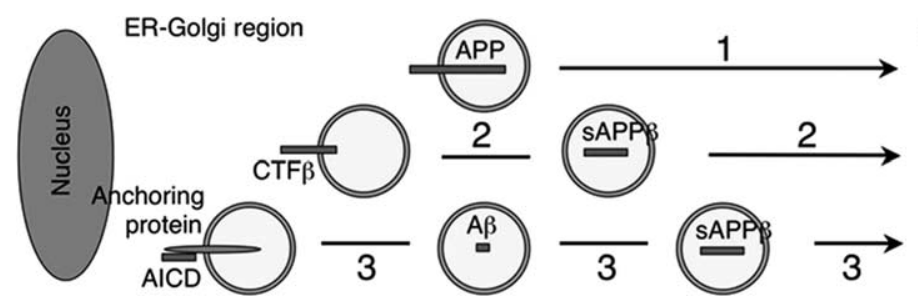

Figure 8. Diagram showing three possible trafficking pathways of APP within neurites. In 1, APP is transported as full-length protein In 2, CTF $\beta$ and sAPP $\beta$ are transported in separate vesicles. In $3, A I C D, A \beta$, and SAPP $\beta$ are transported in separate vesicles. AICD (or pAICD) may bind either to an anchoring protein (as shown in the diagram), or directly to membrane acidic phospholipids (not shown in the diagram). Only the $\beta$-secretase processing pathway is shown. Our data suggest a preponderance of pathways 2 and 3 .

occur almost anywhere along the secretory and recycling pathway: the TGN, the transport vesicle, the plasma membrane, the endosome, and autophagosome (Koo and Squazzo, 1994; Cook et al., 1997; Hartmann et al., 1997; De Strooper and Annaert,

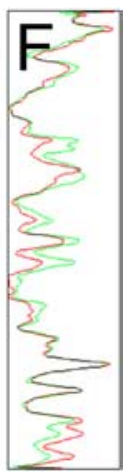

Plasma Membrane

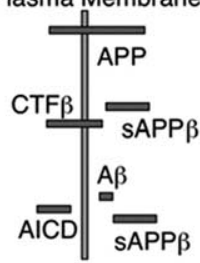

2000; Kamal et al., 2001; Wilson et al., 2002; Yu et al., 2005). Our results are best explained by a scenario in which APP fragments are either generated in the TGN or delivered (from another compartment, such as the endosome) to the TGN and then selectively packaged into distinct transport vesicles. It is likely that fulllength APP is initially targeted to the plasma membrane in the cell soma, then internalized by endocytosis and processed in cell body endosomes (He et al., 2007). The fragments could then be retrotransported to the TGN for packaging into axonal transport vesicles. This pathway is consistent with the currently prevailing view that APP processing primarily occurs in endosomes. Alternatively, it is possible that APP undergoes extensive proteolytic processing early in the secretory pathway, probably as soon as it exits the ER, rather than during recycling via endocytosis. Such a scenario is consistent with recent data showing that, in the in vivo brain, a significant fraction of all proteins found to interact with full-length APP are ER resident proteins (Bai et al., 2007), which suggests that intracellular holo-APP primarily resides in the ER and less in other intracellular compartments. Future studies will elucidate how the different APP fragments are selectively sorted to distinct transport vesicle populations.

\section{All APP-derived polypeptides are}

transported by kinesin- 1 into neurites, but mostly on independent tracks

Kinesin-1 is the main motor that transports both APP and the APP-derived polypeptides (including phosphorylated species) into neurites. This hypothesis is based on data that show that blocking transport by kinesin-1 abolishes accumulation within neurites of APP, as revealed with antibodies that detect epitopes throughout the APP molecule (Yamazaki et al., 1995; Kaether et al., 2000; Peretti et al., 2000; Muresan and Muresan, 2005b). Although KIF17 (a kinesin-2 motor) may interact with the APPbinding protein Mint $1 / \mathrm{X} 11 \alpha$ (Setou et al., 2000), data indicating that this kinesin motor is involved in APP transport along neurites are still lacking. Despite the use of the same motor, the regulation of transport within neurites of the various APP fragments and the characteristics of transport differ significantly. Our results suggest that $\mathrm{N}$-terminal APP fragments are preferentially transported along acetylated microtubules. The selection for a specific class of posttranslationally modified microtubules appears to rely mostly on factors other than the kinesin-1 motor itself. Indeed, all APP-derived polypeptides are carried into neurites by kinesin-1; yet, their transport occurs along distinct sets of microtubules. 
How might kinesin-1 be recruited to the cargo vesicles that contain the different APP fragments and insure selective transport? It is possible that different kinesin-1 motors, differing in the heavy chain or light chain isoforms (Deboer et al., 2008), are recruited to specific cargo vesicles, a hypothesis that remains to be tested. Most likely, different APP-derived polypeptides (or sets of polypeptides) recruit kinesin-1 motors via different scaffolding proteins (Muresan, 2000). Like pAPP, the pCTFs and the pAICD may recruit kinesin-1 via JIP-1 (Muresan and Muresan, 2005a,b), a protein that was recently implicated in axonal development (Dajas-Bailador et al., 2008). Nonphosphorylated CTFs and AICD may recruit kinesin-1 via Fe65, a kinesin-1-binding (Lazarov et al., 2005) and APP-binding (Borg et al., 1996) scaffolding protein that binds with higher affinity to nonphosphorylated compared with pAPP species (Ando et al., 2001). How the presumably soluble ( $\mathrm{p}$ )AICD attaches to the vesicle membrane is not known, and this may involve yet to be identified anchoring proteins. Alternatively, the (p)AICD may directly bind to acidic phospholipids via the $\mathrm{N}$-terminal cluster of positively charged lysine residues present in AICD.

Deciphering how kinesin- 1 is recruited to vesicles that contain $\mathrm{p} 3 / \mathrm{A} \beta$ or $\mathrm{sAPP} \alpha / \beta$, which are inside the vesicle, will be more difficult, because these APP fragments may not directly participate themselves in recruiting the motor machinery.

\section{The pCTFs are transported into filopodia, likely along actin filaments, and may play a role in growth cone turning and advancement}

Interestingly, pCTFs (especially the pAICD) were systematically detected at locations likely to be reached by actin- rather than microtubule-based transport, such as the distal filopodia and the lateral filopodia-like processes. Although the characterization of the mechanism of pCTF transport within filopodia (including identifying the motor that powers this transport) was not the subject of the current study, myosin- $\mathrm{X}$, an unconventional myosin that undergoes intrafilopodial motility (Berg and Cheney, 2002), could, in principle, bind to and power the transport of pCTF-containing cargo. Indeed, myosin-X contains a PTB domain within its FERM (Band 4.1/Ezrin/Radixin/Moesin) domain (Sousa and Cheney, 2005) predicted to bind to the cytoplasmic domain of APP [and (p)CTFs].

Previous studies have proposed that APP may function in regulating some sort of actin-based motility in neurons (Sabo et al., 2001). Extending these studies in an unexpected way, our results suggest that the pCTFs (including the pAICD), not the full-length APP, may play a role in growth cone turning and advancement, processes that involve both actin filaments and microtubules, as well as the action of molecular motors. It is significant that a recent study has implicated JIP-1, the scaffolding protein that is cotransported with pAPP species (Muresan and Muresan, 2005b), in axonal development (Dajas-Bailador et al., 2008). Combined with this study, our results raise the possibility that PCTF/JIP-1 complexes could be involved in regulating growth cone motility, and thus neurite extension, a hypothesis that will be tested in the future.

\section{Technical note}

From a technical perspective, our study emphasizes the benefit of using multiple antibodies to study the intracellular localization of proteins (such as APP) that undergo complex posttranslational modifications. We also draw attention to the fact that the segregation of APP fragments is not detected after overexpression of APP, which suggests that the normal, physiological processing and transport of APP is mostly perturbed at the high APP levels usually attained in transfected cells and some mouse models of $\mathrm{AD}$.

\section{Conclusion}

We have provided evidence that the proteolytic cleavage of APP primarily occurs before its sorting into transport vesicles destined for neuritic delivery and that full-length APP represents only a fraction of the total (full-length plus cleaved) APP present within neuronal processes at any given time. We infer that a significant portion of the full-length APP is only an intermediary product with no function of its own, from which active polypeptides [sAPPs, (p)CTFs, (p)AICD, and A $\beta$ ] are generated before sorting into transport vesicles. Once generated, these polypeptides, some modified by phosphorylation, are packaged into distinct vesicles that travel on distinct cytoskeletal tracks to different destinations, where they exert their specific functions. For example, the pCTFs may play a role in growth cone turning and advancement, traveling on both microtubules and actin filaments. From this perspective, cleavage of APP to produce different functional molecules appears similar to the cleavage of peptide hormone precursors, such as pro-opiomelanocortin, which generates several hormones with distinct activities but has no function as fulllength protein (Alberts et al., 2002). The signaling that regulates the early APP processing and the many roles of the APP fragments remain to be determined.

\section{References}

Alberts B, Johnson A, Lewis J, Raff M, Roberts K, Walter P (2002) Molecular biology of the cell, Ed 4. New York: Garland Science.

Amaratunga A, Fine RE (1995) Generation of amyloidogenic C-terminal fragments during rapid axonal transport in vivo of beta-amyloid precursor protein in the optic nerve. J Biol Chem 270:17268-17272.

Ando K, Iijima KI, Elliott JI, Kirino Y, Suzuki T (2001) Phosphorylationdependent regulation of the interaction of amyloid precursor protein with Fe65 affects the production of beta-amyloid. J Biol Chem 276:40353-40361.

Annaert WG, Levesque L, Craessaerts K, Dierinck I, Snellings G, Westaway D, George-Hyslop PS, Cordell B, Fraser P, De Strooper B (1999) Presenilin 1 controls gamma-secretase processing of amyloid precursor protein in pre-golgi compartments of hippocampal neurons. J Cell Biol 147:277-294.

Bai Y, Markham K, Chen F, Weerasekera R, Watts J, Horne P, Wakutani Y, Mathews PM, Fraser PE, Westaway D, St George-Hyslop P, Schmitt-Ulms G (2007) The in vivo brain interactome of the amyloid precursor protein. Mol Cell Proteomics 7:15-34

Berg JS, Cheney RE (2002) Myosin-X is an unconventional myosin that undergoes intrafilopodial motility. Nat Cell Biol 4:246-250.

Borg JP, Ooi J, Levy E, Margolis B (1996) The phosphotyrosine interaction domains of X11 and FE65 bind to distinct sites on the YENPTY motif of amyloid precursor protein. Mol Cell Biol 16:6229-6241.

Buxbaum JD, Thinakaran G, Koliatsos V, O'Callahan J, Slunt HH, Price DL, Sisodia SS (1998) Alzheimer amyloid protein precursor in the rat hippocampus: transport and processing through the perforant path. J Neurosci 18:9629-9637.

Cao X, Sudhof TC (2001) A transcriptionally [correction of transcriptively] active complex of APP with Fe65 and histone acetyltransferase Tip60. Science 293:115-120.

Capell A, Grunberg J, Pesold B, Diehlmann A, Citron M, Nixon R, Beyreuther K, Selkoe DJ, Haass C (1998) The proteolytic fragments of the Alzheimer's disease-associated presenilin-1 form heterodimers and occur as a 100-150-kDa molecular mass complex. J Biol Chem 273:3205-3211.

Cook DG, Forman MS, Sung JC, Leight S, Kolson DL, Iwatsubo T, Lee VM, Doms RW (1997) Alzheimer's A beta(1-42) is generated in the endoplasmic reticulum/intermediate compartment of NT2N cells. Nat Med 3:1021-1023.

Dajas-Bailador F, Jones EV, Whitmarsh AJ (2008) The JIP1 scaffold protein regulates axonal development in cortical neurons. Curr Biol 18:221-226. 
Deboer SR, You Y, Szodorai A, Kaminska A, Pigino G, Nwabuisi E, Wang B, Estrada-Hernandez T, Kins S, Brady ST, Morfini G (2008) Conventional Kinesin holoenzymes are composed of heavy and light chain homodimers. Biochemistry 47:4535-4543.

DeGiorgio LA, Shimizu Y, Chun HS, Kim YS, Sugama S, Son JH, Joh TH, Volpe BT (2002) Amyloid precursor protein gene disruption attenuates degeneration of substantia nigra compacta neurons following axotomy. Brain Res 938:38-44.

De Strooper B, Annaert W (2000) Proteolytic processing and cell biological functions of the amyloid precursor protein. J Cell Sci 113:1857-1870.

Dunn S, Morrison EE, Liverpool TB, Molina-Paris C, Cross RA, Alonso MC, Peckham M (2008) Differential trafficking of Kif5c on tyrosinated and detyrosinated microtubules in live cells. J Cell Sci 121:1085-1095.

Goldsbury C, Mocanu MM, Thies E, Kaether C, Haass C, Keller P, Biernat J, Mandelkow E, Mandelkow EM (2006) Inhibition of APP Trafficking by Tau Protein does not Increase the generation of amyloid-beta peptides. Traffic 7:873-888.

Goslin K, Banker G (1991) Characterizing and studying neuronal cultures. In: Culturing nerve cells (Banker G, Goslin K, eds), pp 75-109. Cambridge, MA: MIT.

Grundke-Iqbal I, Iqbal K, George L, Tung YC, Kim KS, Wisniewski HM (1989) Amyloid protein and neurofibrillary tangles coexist in the same neuron in Alzheimer disease. Proc Natl Acad Sci USA 86:2853-2857.

Haass C, Selkoe DJ (2007) Soluble protein oligomers in neurodegeneration: lessons from the Alzheimer's amyloid beta-peptide. Nat Rev Mol Cell Biol 8:101-112.

Hartmann T, Bieger SC, Bruhl B, Tienari PJ, Ida N, Allsop D, Roberts GW, Masters CL, Dotti CG, Unsicker K, Beyreuther K (1997) Distinct sites of intracellular production for Alzheimer's disease A beta40/42 amyloid peptides. Nat Med 3:1016-1020.

He X, Cooley K, Chung CH, Dashti N, Tang J (2007) Apolipoprotein receptor 2 and X11 alpha/beta mediate apolipoprotein E-induced endocytosis of amyloid-beta precursor protein and beta-secretase, leading to amyloidbeta production. J Neurosci 27:4052-4060.

Hilbich C, Monning U, Grund C, Masters CL, Beyreuther K (1993) Amyloid-like properties of peptides flanking the epitope of amyloid precursor protein-specific monoclonal antibody 22C11. J Biol Chem 268:26571-26577.

Iijima K, Ando K, Takeda S, Satoh Y, Seki T, Itohara S, Greengard P, Kirino Y, Nairn AC, Suzuki T (2000) Neuron-specific phosphorylation of Alzheimer's beta-amyloid precursor protein by cyclin-dependent kinase 5 . J Neurochem 75:1085-1091.

Kaether C, Skehel P, Dotti CG (2000) Axonal membrane proteins are transported in distinct carriers: a two-color video microscopy study in cultured hippocampal neurons. Mol Biol Cell 11:1213-1224.

Kamal A, Stokin GB, Yang Z, Xia C, Goldstein LS (2000) Axonal transport of amyloid precursor protein is mediated by direct binding to the kinesin light chain subunit of kinesin-I [In Process Citation]. Neuron 28:449-459.

Kamal A, Almenar-Queralt A, LeBlanc JF, Roberts EA, Goldstein LSB (2001) Kinesin-mediated axonal transport of a membrane compartment containing beta-secretase and presenilin-1 requires APP. Nature 414:643-648.

Kim J, Kleizen B, Choy R, Thinakaran G, Sisodia SS, Schekman RW (2007) Biogenesis of gamma-secretase early in the secretory pathway. J Cell Biol 179:951-963

Kimberly WT, Zheng JB, Town T, Flavell RA, Selkoe DJ (2005) Physiological regulation of the beta-amyloid precursor protein signaling domain by c-Jun N-terminal kinase JNK3 during neuronal differentiation. J Neurosci 25:5533-5543.

Kinoshita A, Whelan CM, Smith CJ, Berezovska O, Hyman BT (2002) Direct visualization of the gamma secretase-generated carboxyl-terminal domain of the amyloid precursor protein: association with Fe65 and translocation to the nucleus. J Neurochem 82:839-847.

Konecna A, Frischknecht R, Kinter J, Ludwig A, Steuble M, Meskenaite V, Indermuhle $\mathrm{M}$, Engel $\mathrm{M}$, Cen $\mathrm{C}$, Mateos JM, Streit $\mathrm{P}$, Sonderegger $\mathrm{P}$ (2006) Calsyntenin-1 docks vesicular cargo to kinesin-1. Mol Biol Cell 17:3651-3663.

Koo EH, Squazzo SL (1994) Evidence that production and release of amyloid beta-protein involves the endocytic pathway. J Biol Chem 269:17386-17389.

Lamb BT, Call LM, Slunt HH, Bardel KA, Lawler AM, Eckman CB, Younkin
SG, Holtz G, Wagner SL, Price DL, Sisodia SS, Gearhart JD (1997) Altered metabolism of familial Alzheimer's disease-linked amyloid precursor protein variants in yeast artificial chromosome transgenic mice. Hum Mol Genet 6:1535-1541.

Lazarov O, Lee M, Peterson DA, Sisodia SS (2002) Evidence that synaptically released beta-amyloid accumulates as extracellular deposits in the hippocampus of transgenic mice. J Neurosci 22:9785-9793.

Lazarov O, Morfini GA, Lee EB, Farah MH, Szodorai A, DeBoer SR, Koliatsos VE, Kins S, Lee VM, Wong PC, Price DL, Brady ST, Sisodia SS (2005) Axonal transport, amyloid precursor protein, kinesin-1, and the processing apparatus: revisited. J Neurosci 25:2386-2395.

Lee MS, Kao SC, Lemere CA, Xia W, Tseng HC, Zhou Y, Neve R, Ahlijanian MK, Tsai LH (2003) APP processing is regulated by cytoplasmic phosphorylation. J Cell Biol 163:83-95.

Lehman EJ, Kulnane LS, Lamb BT (2003) Alterations in beta-amyloid production and deposition in brain regions of two transgenic models. Neurobiol Aging 24:645-653.

Li X, Low SH, Miura M, Weimbs T (2002) SNARE expression and localization in renal epithelial cells suggest mechanism for variability of trafficking phenotypes. Am J Physiol Renal Physiol 283:F1111-F1122.

Li Y, Hou LX, Aktiv A, Dahlstrom A (2005) Immunohistochemical characterisation of differentiated CAD cells: expression of peptides and chromogranins. Histochem Cell Biol 124:25-33.

Luduena RF, Banerjee A, Khan IA (1992) Tubulin structure and biochemistry. Curr Opin Cell Biol 4:53-57.

Ma QH, Futagawa T, Yang WL, Jiang XD, Zeng L, Takeda Y, Xu RX, Bagnard D, Schachner M, Furley AJ, Karagogeos D, Watanabe K, Dawe GS, Xiao ZC (2008) A TAG1-APP signalling pathway through Fe65 negatively modulates neurogenesis. Nat Cell Biol 10:283-294.

Muresan V (2000) One axon, many kinesins: What's the logic? J Neurocytol 29:799-818.

Muresan Z, Muresan V (2004) A phosphorylated, carboxy-terminal fragment of $\{$ beta $\}$-amyloid precursor protein localizes to the splicing factor compartment. Hum Mol Genet 13:475-488.

Muresan Z, Muresan V (2005a) c-Jun NH2-terminal kinase-interacting protein-3 facilitates phosphorylation and controls localization of amyloid-beta precursor protein. J Neurosci 25:3741-3751.

Muresan Z, Muresan V (2005b) Coordinated transport of phosphorylated amyloid-beta precursor protein and c-Jun NH2-terminal kinaseinteracting protein-1. J Cell Biol 171:615-625.

Muresan Z, Muresan V (2006) Neuritic deposits of amyloid-\{beta\} peptide in a subpopulation of central nervous system-derived neuronal cells. Mol Cell Biol 26:4982-4997.

Muresan Z, Muresan V (2007) The amyloid-beta precursor protein is phosphorylated via distinct pathways during differentiation, mitosis, stress, and degeneration. Mol Biol Cell 18:3835-3844.

Muresan Z, Muresan V (2008) Seeding neuritic plaques from the distance: a possible role for brainstem neurons in the development of Alzheimer's disease pathology. Neurodegener Dis 5:250-253.

Peretti D, Peris L, Rosso S, Quiroga S, Caceres A (2000) Evidence for the involvement of KIF4 in the anterograde transport of L1-containing vesicles. J Cell Biol 149:141-152.

Qi Y, Wang JK, McMillian M, Chikaraishi DM (1997) Characterization of a CNS cell line, CAD, in which morphological differentiation is initiated by serum deprivation. J Neurosci 17:1217-1225.

Reed NA, Cai D, Blasius TL, Jih GT, Meyhofer E, Gaertig J, Verhey KJ (2006) Microtubule acetylation promotes kinesin-1 binding and transport. Curr Biol 16:2166-2172.

Roy S, Zhang B, Lee VM, Trojanowski JQ (2005) Axonal transport defects: a common theme in neurodegenerative diseases. Acta Neuropathol (Berl) 109:5-13.

Sabo SL, Ikin AF, Buxbaum JD, Greengard P (2001) The Alzheimer amyloid precursor protein (APP) and FE65, an APP-binding protein, regulate cell movement. J Cell Biol 153:1403-1414.

Sabo SL, Ikin AF, Buxbaum JD, Greengard P (2003) The amyloid precursor protein and its regulatory protein, FE65, in growth cones and synapses in vitro and in vivo. J Neurosci 23:5407-5415.

Sambamurti K, Refolo LM, Shioi J, Pappolla MA, Robakis NK (1992) The Alzheimer's amyloid precursor is cleaved intracellularly in the trans-Golgi network or in a post-Golgi compartment. Ann NY Acad Sci 674:118-128.

Schaefer AW, Kabir N, Forscher P (2002) Filopodia and actin arcs guide 
the assembly and transport of two populations of microtubules with unique dynamic parameters in neuronal growth cones. J Cell Biol 158:139-152.

Selkoe DJ (1999) Translating cell biology into therapeutic advances in Alzheimer's disease. Nature 399:A23-31.

Setou M, Nakagawa T, Seog DH, Hirokawa N (2000) Kinesin superfamily motor protein KIF17 and mLin-10 in NMDA receptor- containing vesicle transport. Science 288:1796-1802.

Sousa AD, Cheney RE (2005) Myosin-X: a molecular motor at the cell's fingertips. Trends Cell Biol 15:533-539.

Stamer K, Vogel R, Thies E, Mandelkow E, Mandelkow EM (2002) Tau blocks traffic of organelles, neurofilaments, and APP vesicles in neurons and enhances oxidative stress. J Cell Biol 156:1051-1063.

Walter J, Fluhrer R, Hartung B, Willem M, Kaether C, Capell A, Lammich S, Multhaup G, Haass C (2001) Phosphorylation regulates intracellular trafficking of beta-secretase. J Biol Chem 276:14634-14641.

Weidemann A, Konig G, Bunke D, Fischer P, Salbaum JM, Masters CL,
Beyreuther K (1989) Identification, biogenesis, and localization of precursors of Alzheimer's disease A4 amyloid protein. Cell 57:115-126.

Wilson CA, Doms RW, Zheng H, Lee VM (2002) Presenilins are not required for Abeta42 production in the early secretory pathway. Nat Neurosci 5:849-855.

Yamazaki T, Selkoe DJ, Koo EH (1995) Trafficking of cell surface betaamyloid precursor protein: retrograde and transcytotic transport in cultured neurons. J Cell Biol 129:431-442.

Yang Y, Varvel NH, Lamb BT, Herrup K (2006) Ectopic cell cycle events link human Alzheimer's disease and amyloid precursor protein transgenic mouse models. J Neurosci 26:775-784.

Yu WH, Cuervo AM, Kumar A, Peterhoff CM, Schmidt SD, Lee JH, Mohan PS, Mercken M, Farmery MR, Tjernberg LO, Jiang Y, Duff K, Uchiyama Y, Naslund J, Mathews PM, Cataldo AM, Nixon RA (2005) Macroautophagy - a novel Beta-amyloid peptide-generating pathway activated in Alzheimer's disease. J Cell Biol 171:87-98.

Zar JH (1999) Biostatistical analysis. Upper Saddler River, NJ: Prentice Hall. 